\title{
Computational Prediction of Electronic and Photovoltaic Properties of Anthracene-Based Organic Dyes for Dye-Sensitized Solar Cells
}

\author{
Hongbo Wang, ${ }^{1}$ Qian Liu, ${ }^{2}$ Dejiang Liu, ${ }^{3}$ Runzhou Su ${ }^{D},{ }^{1}$ Jinglin Liu $\left(\mathbb{D},{ }^{4}\right.$ and Yuanzuo Li ${ }^{1}{ }^{1}$ \\ ${ }^{1}$ College of Science, Northeast Forestry University, Harbin, Heilongjiang 150040, China \\ ${ }^{2}$ Department of Applied Physics, Xi'an University of Technology, Xi'an 710054, China \\ ${ }^{3}$ Life Science College, Jiamusi University, Jiamusi, Heilongjiang 154007, China \\ ${ }^{4}$ College of Science, Jiamusi University, Jiamusi, Heilongjiang 154007, China
}

Correspondence should be addressed to Runzhou Su; 13503631076@163.com, Jinglin Liu; jinglinliujms@yeah.net, and Yuanzuo Li; yzli@nefu.edu.cn

Received 17 March 2018; Revised 27 May 2018; Accepted 3 June 2018; Published 1 August 2018

Academic Editor: K. R. Justin Thomas

Copyright (c) 2018 Hongbo Wang et al. This is an open access article distributed under the Creative Commons Attribution License, which permits unrestricted use, distribution, and reproduction in any medium, provided the original work is properly cited.

\begin{abstract}
Three kinds of anthracene-based organic dyes for dye-sensitized solar cells (DSSCs) were studied, and their structures are based on a push-pull framework with anthracenyl diphenylamine as the donor connected to a carboxyphenyl or carboxyphenylbromothiazole (BTZ) as the acceptor via an acetylene bridge. The photoelectric properties of the three dyes were investigated using density functional theory (DFT). The simulations indicate that the improvement of anthracene-based dyes (the addition of BTZ and the change of alkyl groups to alkoxy chains) can reduce the energy gap and produce a red shift. This structural modification also improves the light capturing and the electron injection capability, making it excellent in photoelectric conversion efficiency (PCE). In addition, twelve molecules have been designed to regulate photovoltaic performance.
\end{abstract}

\section{Introduction}

With the depletion of traditional fossil fuels and environmental pollution, green energy has aroused widespread concern in academia [1]. Therefore, nonpolluting solar energy has become the most promising alternative energy source [2]. Compared with traditional inorganic solar cells based on silicon crystal, dye-sensitized solar cells (DSSCs) have the advantages of easy synthesis, low cost, and high conversion efficiency [3, 4]. Since the first report in 1991, DSSCs have a high PCE [5]. In general, a typical DSSC device consists of a titania semiconductor film, a dye sensitizer, a redox electrolyte, a counterelectrode, and a transparent conductive substrate [6-8]. The dye is mainly divided into metalcontaining ruthenium dyes [9], porphyrin dyes [10], and metal-free organic dyes [11]. As an important part of DSSCs, sensitizers play an important role in capturing sunlight and the electron transfer. Among them, ruthenium (II) polypyridyl complexes are considered to be efficient and stable sensitizers with a power conversion efficiency (PCE) above $11 \%$ at AM1.5G [12, 13]. However, the scarcity, high cost, and toxicity of ruthenium metal limit the widespread use of such sensitizers in DSSCs. In addition, the zinc porphyrin dye is more than $12 \%$ efficient in $\mathrm{Co}^{\mathrm{II}} / \mathrm{Co}^{\mathrm{III}}$ electrolytes under standard conditions, which is considered to be a very promising sensitizer $[14,15]$. In recent years, perovskite solar cells have become another potential photovoltaic approach with efficiency of over $20 \%$ under AM1.5G light sources and dim light irradiation $[16,17]$. However, solution of the instability of devices and pollution for environment caused from raw materials are still a challenge [18-20]. Metal-free organic dyes are characterized by low cost, ease of purification, and flexible molecular design [21], and metal-free sensitizers are designed with donor- $\pi$-acceptor $(D-\pi-A), D-\pi-A-A$, or D-A- $\pi-A$, which can lead to light-induced charge separation, improvement in stability, and optimization of the energy level of the dye from structure modifications [22-25]. To date, PCE of such kind of organic dyes has reportedly reached 
$14 \%$ [26]. Due to a large number of functional groups available for molecular design, there still is much work for DSSC performance improvement.

Molecular materials with the anthracene structure have good stability and special luminescent properties, showing a bright blue electroluminescence [27-29]. However, there are relatively few studies on the photoelectric properties of anthracene-based molecules. There are few metal-free sensitizers featuring a 9,10-disubsituted anthracene entity as a conjugated spacer between electron donor and acceptor moieties, and the best PCE is 7.03\% [30-33]. Recently, a dye containing 2,6-conjugated anthracene showed a photoconversion efficiency of $9.11 \%$ [34] at 1 sun condition, which is the highest PCE reported by anthracene dyes. Mai and coworkers [35] have synthesized a simple D- $\pi$-A sensitizer (MS3), which is based on a 9,10-disubstituted anthracene entity with an optical efficiency of $5.84 \%$ at AM1.5G. Based on the MS3 sensitizer, TY3 (D- $\pi-A)$ and TY6 (D-A- $\pi-A)$ were also synthesized. TY6 has the best PCE (up to $8.80 \%$ ) [36]. To study the relationship between structure and properties, we used the theory of density functional theory (DFT) and time-dependent density functional theory (TD-DFT) to calculate the three-molecular-geometry, electron injection, dye regeneration, and optical properties, and results confirmed that its excellent performance was due to its excellent $J_{\mathrm{SC}}$ and $V_{\mathrm{OC}}$ characteristics. In addition, a series of design molecules based on TY6 were investigated to improve optical response and electron injection.

\section{Computational Details}

The ground-state geometries of three molecules were optimized by DFT//B3LYP/6-31G(d) level [37-40]. In order to simulate the more realistic performance of dye-sensitized solar cells, the related calculations were performed in the solvent condition (THF) by using the C-PCM [41] method. Frequency calculations showed the minima on the potential energy surface for optimization. The bond lengths, dihedral angles, energy gaps, frontier molecular orbitals, electron injection, and recombination of the optimized molecules were calculated. The absorption spectra, transition energies, and oscillator strengths of molecules were obtained with TD-DFT [42] by using the CAM-B3LYP [43] functional at the same basis set as the ground state. Three excited states are calculated, including the first excited state (S1), the second excited state (S2), and the third excited state (S3). The natural bond orbital (NBO) analysis [44] for the charge difference between the ground state and the excited state was carried out at the B3LYP/6-31G(d) level using the NBO 3.1 program. By introduction of an electron-withdrawing group in the acceptor, it hoped that the molecular modification can attract electrons and promote an intramolecular charge transfer from donor to acceptor, further leading to better electron injection into the conduction band of $\mathrm{TiO}_{2}$. Therefore, twelve new dye molecules were designed by introducing $\mathrm{CN}, \mathrm{F}$, and $\mathrm{CF}_{3}$ into the acceptor of the TY6 molecule, and the correlation calculations were made using the same method as the original dye molecule. All calculations are made through the Gaussian 09 package [45].

\section{Analysis}

3.1. Geometric Structures. Figure 1 shows the optimized ground-state molecular structure. As shown in Figure 1(a), MS3 is an original molecule, and TY3 is obtained by converting the C-6 alkyl chain of MS3 to the carbon alloy group. Based on the TY3 molecule, benzotriazole (BTZ) was introduced between the acetylene bridge and benzoic acid. In order to reduce the aggregation of sensitizer and improve the performance, a long alkyl chain was introduced into the $\mathrm{N}$ position of BTZ to obtain TY6. Figure 1(b) shows the ground-state structures of the three optimized molecules in the THF solvent. In order to facilitate the calculation, the long carbon chains on the donor were pruned appropriately. Both MS3 and TY3 are typical D- $\pi$-A structures; the donor and the $\pi$-bridge are the amino donor and the acetylene bridge, and the acceptor is benzoic acid. TY6 is the D-A- $\pi-\mathrm{A}$ structure, in which an additional acceptor is added between the acetylene bridge and benzoic acid. Table 1 shows the bond length and dihedral angle in gas and solvent (THF), respectively. For example, in gas, the dihedral angles of MS3 $\angle \mathrm{C} 1$ C2-N3-C4 and $\angle \mathrm{C} 2-\mathrm{N} 3-\mathrm{C} 4-\mathrm{C} 5$ were $33.16^{\circ}$ and $70.94^{\circ}$, and the average value of the two warped dihedral angles is $52.05^{\circ}$. In the same way, the calculated mean values of the donor dihedral angles for TY3 and TY6 are $52.60^{\circ}$ and $52.40^{\circ}$. It shows that the donor has a distorted structure. Dyes TY3 and TY6 are more largely distorted than the original molecule MS3, which can reduce the aggregation of dye molecules. At the same time, the three molecules have similar results in solvent: TY3 $\left(52.66^{\circ}\right)$ and TY6 $\left(52.33^{\circ}\right)$ are greater than the donor dihedral angle of MS3 $\left(51.88^{\circ}\right)$. In gas, the bond lengths of the three molecules N3-C4 and C10-C11 are smaller than those of the single bond (i.e., C-C: $1.530 \AA$ [46], N-C: $1.471 \AA$ [47]). In general, the stability of a molecule can be judged by the length of the bond [48]. The shorter the bond length is, the more stable the molecule becomes. By comparison, the bond lengths of TY3 and TY6 are less than that of MS3, and the same results are also observed in solvent condition; therefore, TY3 and TY6 molecules are more stable.

3.2. Energy Levels. Table 2 shows the HOMO, HOMO-1, $\mathrm{LUMO}, \mathrm{LUMO}+1$, and energy gaps $\left(\Delta_{H-L}\right)$ for MS3, TY3, and TY6. In the gas phase, the HOMO order of the molecule is as follows: TY6 $(-4.59 \mathrm{eV})>\mathrm{TY} 3 \quad(-4.67 \mathrm{eV})>\mathrm{MS} 3$ $(-4.91 \mathrm{eV})$. LUMO energy is arranged in the following order: TY3 $(-2.26 \mathrm{eV})>$ TY6 $(-2.30 \mathrm{eV})>\mathrm{MS} 3 \quad(-2.33 \mathrm{eV})$. The energy gap is arranged in the following order: MS3 $(2.58 \mathrm{eV})>$ TY3 $(2.41 \mathrm{eV})>$ TY $6(2.29 \mathrm{eV})$. As shown in Figure 2, we can find that LUMO of the three molecules has little change, and thus, the gradual increase in the HOMO energy level leads to the decrease in energy gap. The reduction in the energy gap also favors the red-shifted absorption peak in the UV absorption spectrum (data in Table 3 and spectra nature in Figure 3). Therefore, the absorption peak of TY6 will have a significantly red shift.

In solvent condition, for MS3 the energy of $\mathrm{HOMO}$ $(-5.01 \mathrm{eV})$ is reduced by $0.10 \mathrm{eV}$ compared with that in the gas condition, and the energy of LUMO $(-2.44 \mathrm{eV})$ is 


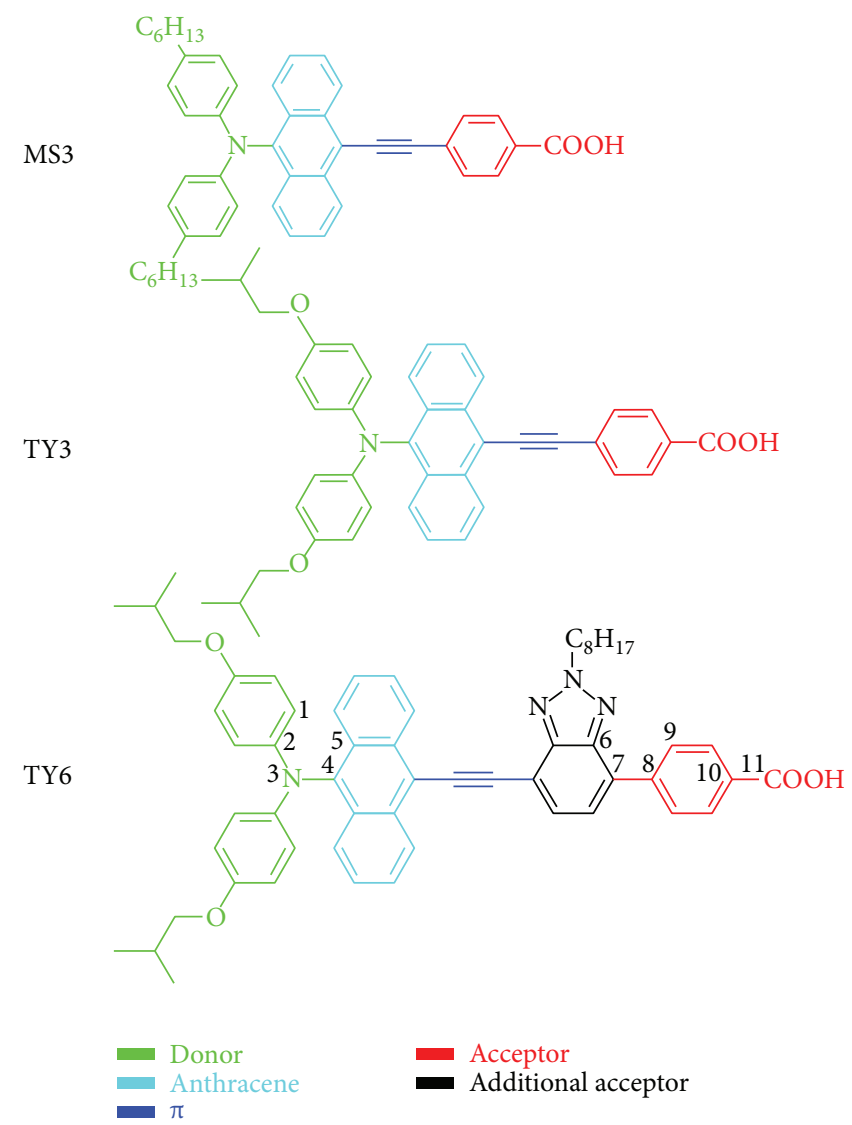

(a)
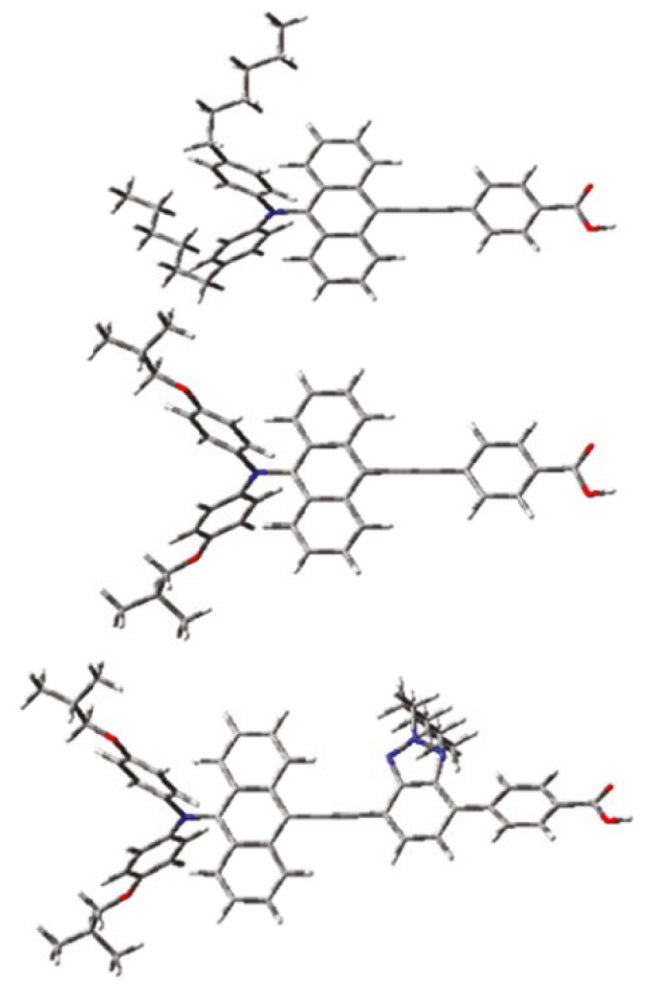

(b)

Figure 1: (a) Chemical structures of MS3, TY3, and TY6. (b) Side view for dyes optimized at the B3LYP/6-31G(d) level. 
TABLe 1: Selected bond lengths $(\AA)$ and dihedral angles $\left({ }^{\circ}\right)$ of MS3, TY3, and TY6.

\begin{tabular}{lccccccc}
\hline & & \multicolumn{2}{c}{ MS3 } & \multicolumn{2}{c}{ TY3 } & TY6 \\
& & Gas & Solvent & Gas & Solvent & Gas & Solvent \\
\hline \multirow{2}{*}{ Dihedral angle } & C1-C2-N3-C4 & 33.16 & 32.87 & 34.88 & 35.05 & 35.20 & 35.45 \\
& C2-N3-C4-C5 & 70.94 & 70.89 & 70.32 & 70.27 & 69.60 & 69.20 \\
\hline \multirow{2}{*}{ Bond length } & N3-C4 & 1.431 & 1.431 & 1.429 & 1.428 & 1.429 & 1.428 \\
& C10-C11 & 1.484 & 1.484 & 1.483 & 1.484 & 1.483 \\
\hline
\end{tabular}

TABLE 2: Frontier molecular orbital energies and energy gaps of MS3, TY3 and TY6.

\begin{tabular}{lcccccc}
\hline & \multicolumn{2}{c}{ MS3 } & \multicolumn{2}{c}{ TY3 } & \multicolumn{2}{c}{ TY6 } \\
& $\begin{array}{l}\text { Gas } \\
(\mathrm{eV})\end{array}$ & $\begin{array}{c}\text { Solvent } \\
(\mathrm{eV})\end{array}$ & $\begin{array}{c}\text { Gas } \\
(\mathrm{eV})\end{array}$ & $\begin{array}{c}\text { Solvent } \\
(\mathrm{eV})\end{array}$ & $\begin{array}{c}\text { Gas } \\
(\mathrm{eV})\end{array}$ & $\begin{array}{c}\text { Solvent } \\
(\mathrm{eV})\end{array}$ \\
\hline $\mathrm{H}-1$ & -5.46 & -5.56 & -5.31 & -5.46 & -5.16 & -5.37 \\
$\mathrm{H}$ & -4.91 & -5.01 & -4.67 & -4.81 & -4.59 & -4.77 \\
$\mathrm{~L}$ & -2.33 & -2.44 & -2.26 & -2.42 & -2.30 & -2.49 \\
L+1 & -1.41 & -1.54 & -1.36 & -1.52 & -1.63 & -1.83 \\
Gap & 2.58 & 2.57 & 2.41 & 2.39 & 2.29 & 2.28 \\
\hline
\end{tabular}

reduced by $0.11 \mathrm{eV}$ compared with that in the gas condition. Therefore, the energy gap $(2.58 \mathrm{eV})$ in solvent is lower than the energy gap in gas $(2.57 \mathrm{eV})$. Similarly, dyes TY3 and TY6 also show the same change, and the results in solvent are better than those in the gas phase, and the energy gap is arranged in the following order: MS3 $(2.57 \mathrm{eV})>\mathrm{TY} 3$ $(2.39 \mathrm{eV})>$ TY6 $(2.28 \mathrm{eV})$. TY6 still has a smaller energy gap. The frontier molecular orbitals of three molecules are shown in Figure 4, which indicates the HOMO and LUMO of the three molecules and the distribution area of the electron density. As a whole, the electron density of HOMO is mainly located near the donor and the $\pi$-bridge, and the electron density of LUMO is mainly located near the $\pi$-bridge and the acceptor. HOMO-1 is lower than HOMO, and the electron density is dispersed in Figure 2. LUMO+1 is higher than LUMO, and its electron density is mainly concentrated on the $\pi$-bridge and the acceptor. Therefore, it can be concluded that the intramolecular charge transfer (ICT) exists in the dye molecule when the electron is transferred from the donor to the acceptor.

Figure 2 shows the orbital energy levels of three molecules. In the gas phase, the HOMO energy $(-4.91 \mathrm{eV})$ of MS3 is lower than the energy of $I^{-} / I_{3}^{-}(-4.85 \mathrm{eV})$, while the HOMO energy of TY3 $(-4.67 \mathrm{eV})$ and TY6 $(-4.59 \mathrm{eV})$ is higher than that of $I^{-} / I_{3}^{-}$. This shows that TY3 and TY6 can more easily recover electrons from electrolytes. The energies of LUMO of three dye molecules are lower than the conduction band energy of $\mathrm{TiO}_{2}(-4.00 \mathrm{eV})$, which indicates that electrons can be successfully injected into $\mathrm{TiO}_{2}$ from the excited state of dye molecules. One of the most important characteristics in the excellent ICT is charge separation. The charge distribution of HOMO and LUMO can promote the transfer of electrons (see Figure 4). In order to investigate the characteristics of ICT, we used the charge density difference $(\mathrm{CDD})$ to show the change of the electron density between the ground state and the excited state. It can characterize CT in organic molecular systems $[49,50]$, which clearly reflects the direction of the electrons. Taking the first excited state of MS3 as an example, the donor is covered with green holes, and the acceptor is covered with red electron (see Figure 3). Hole and electron are alternately distributed in the $\pi$-bridge moiety, and TY3 also shows similar results. For TY6, the S1 of CDD showed electron transfer is from donor to $\pi$-bridge, and for S2 week electron move to auxiliary acceptor BTZ and acceptor benzoic acid; wherefore, the S3 of CDD showed that the green holes make a shift from the donor to the $\pi$-bridge, and the red electrons transfer from the $\pi$-bridge to auxiliary acceptor BTZ and acceptor benzoic acid. The results show that there is a significant charge separation between the donor and the acceptor, which is considered as an ICT feature.

3.3. Absorption Spectrum. Table 3 lists the calculated absorption peaks, transition energies, and oscillator strengths (only discuss the state of $f>0.1$ ). In the $U V-V i s$ spectral region, the main absorption band was found to be the first excited state (S1 state). The first excited state (S1) of MS3 corresponds to the electron transition from HOMO to LUMO. It can be seen from Figure 4 that electrons transfer from the amino donor to the benzoic acid acceptor. In gas, the maximum absorption peak is $452 \mathrm{~nm}$ (463 nm in solvent), and the oscillator strength is 0.5880 (0.7021 in solvent). For the higher excited state (S2), the absorption intensity is lower than in S1, and the maximum absorption peak is $375 \mathrm{~nm}$ $(f=0.1800)$, which shows the electron transition process from HOMO-1 to LUMO. For TY3, the maximum absorption peak in gas $\mathrm{S} 1$ is $470 \mathrm{~nm}$ (481 nm in solvent), and the oscillator strength is 0.5112 (0.6182 in solvent), which shows the electron transition process from HOMO to LUMO. For the second excited state (S2), the maximum absorption peak is $384 \mathrm{~nm}(f=0.2814)$, which shows the electron transition process from HOMO-1 to LUMO. For TY6, the maximum absorption peak of $\mathrm{S} 1$ in gas is $481 \mathrm{~nm}$ ( $494 \mathrm{~nm}$ in solvent). The oscillator strength is 0.8886 (0.9799 in solvent), which indicates the electron transition process from $\mathrm{HOMO}$ to LUMO. For the higher excited state (S2 and S3), the maximum absorption peak of S2 is $395 \mathrm{~nm}(f=0.3714)$, showing an electron transition from HOMO-1 to LUMO. The maximum absorption peak of S3 is $344 \mathrm{~nm}(f=0.1763)$, which shows the electron transition process from HOMO to LUMO+1. According to the data in Table 3, the maximum absorption peak value of the three molecules in gas is as follows: TY6 $(481 \mathrm{~nm})>$ TY3 $(470 \mathrm{~nm})>$ MS3 $(452 \mathrm{~nm})$. The UV-Vis spectra are given in Figure 5. Compared with 


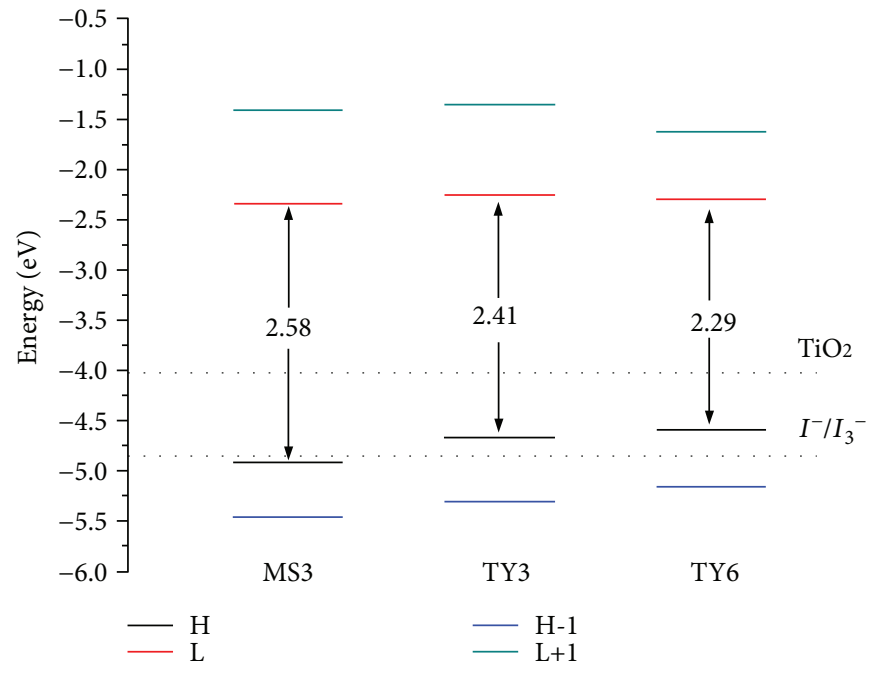

FIGURE 2: Frontier molecular orbital energies and energy gaps of MS3, TY3, and TY6.

TABLE 3: Calculated transition energies and oscillator strengths of MS3, TY3, and TY6.

\begin{tabular}{|c|c|c|c|c|c|c|}
\hline Dye & & State & Contribution Mo & $E(\mathrm{eV})$ & Absorption peak $\lambda(\mathrm{nm})$ & Strength $f$ \\
\hline \multirow{9}{*}{ Gas } & MS3 & 1 & $0.68162 / \mathrm{H} \rightarrow \mathrm{L}$ & 2.75 & 452 & 0.5880 \\
\hline & & 2 & $0.67414 / \mathrm{H}-1 \rightarrow \mathrm{L}$ & 3.31 & 375 & 0.1800 \\
\hline & & 3 & $0.40992 / \mathrm{H} \rightarrow \mathrm{L}+2$ & 3.88 & 320 & 0.0038 \\
\hline & TY3 & 1 & $0.67550 / \mathrm{H} \rightarrow \mathrm{L}$ & 2.64 & 470 & 0.5112 \\
\hline & & 2 & $0.67701 / \mathrm{H}-1 \rightarrow \mathrm{L}$ & 3.23 & 384 & 0.2814 \\
\hline & & 3 & $0.45755 / \mathrm{H}-3 \rightarrow \mathrm{L}$ & 3.23 & 321 & 0.0019 \\
\hline & TY6 & 1 & $0.63853 / \mathrm{H} \rightarrow \mathrm{L}$ & 2.58 & 481 & 0.8886 \\
\hline & & 2 & $0.62381 / \mathrm{H}-1 \rightarrow \mathrm{L}$ & 3.14 & 395 & 0.3714 \\
\hline & & 3 & $0.50506 / \mathrm{H} \rightarrow \mathrm{L}+1$ & 3.61 & 344 & 0.1763 \\
\hline \multirow{9}{*}{ Solvent } & MS3 & 1 & $0.68199 / \mathrm{H} \rightarrow \mathrm{L}$ & 2.68 & 463 & 0.7021 \\
\hline & & 2 & $0.67305 / \mathrm{H}-1 \rightarrow \mathrm{L}$ & 3.27 & 380 & 0.1855 \\
\hline & & 3 & $0.40157 / \mathrm{H} \rightarrow \mathrm{L}+2$ & 3.87 & 320 & 0.008 \\
\hline & TY3 & 1 & $0.67467 / \mathrm{H} \rightarrow \mathrm{L}$ & 2.58 & 481 & 0.6182 \\
\hline & & 2 & $0.67454 / \mathrm{H}-1 \rightarrow \mathrm{L}$ & 3.18 & 390 & 0.2912 \\
\hline & & 3 & $0.46359 / \mathrm{H}-3 \rightarrow \mathrm{L}$ & 3.86 & 321 & 0.0036 \\
\hline & TY6 & 1 & $0.64236 / \mathrm{H} \rightarrow \mathrm{L}$ & 2.51 & 494 & 0.9799 \\
\hline & & 2 & $0.62799 / \mathrm{H}-1 \rightarrow \mathrm{L}$ & 3.10 & 401 & 0.4138 \\
\hline & & 3 & $0.46269 / \mathrm{H} \rightarrow \mathrm{L}+1$ & 3.58 & 346. & 0.2365 \\
\hline
\end{tabular}

MS3 (452 nm) in gas, TY3 has a red shift $(18 \mathrm{~nm})$, and TY6 has a larger red shift $(29 \mathrm{~nm})$. This result indicates that the reduction in the energy gap favors the red-shifted absorption peak. The peak ranges are between 500 and $700 \mathrm{~nm}$, which is helpful for effectively absorbing sunlight. It can be seen from Figure 5 that TY6 has the most pronounced red-shift absorption with the highest molar absorption coefficient. From the gas to solvent condition, absorption peaks of the red shift is approximately $11 \mathrm{~nm}$, and the molar extinction coefficient is also increased (Figure 5). Performance in solvent is better than in gas. In summary, TY6 absorbs sunlight more efficiently than other molecules do, which may lead to higher PCE.
3.4. Chemical Reactivity Parameters. Ionization potential (IP) and electron affinity (EA) are important data for measuring the injection ability of holes and electrons [51-53]. The calculated IPs and EAs are listed in Table 4. In gas, the IPs of the three molecules are arranged in the order TY6 $(5.49 \mathrm{eV})<\mathrm{TY} 3(5.65 \mathrm{eV})<\mathrm{MS} 3(5.89 \mathrm{eV})$. In addition, the reduction in IP means the increase in contribution ability. In gas, the EAs of the three molecules are arranged in the order TY6 $(1.40 \mathrm{eV})>\operatorname{MS} 3(1.34 \mathrm{eV})>\mathrm{TY} 3(1.22 \mathrm{eV})$. The greater the value of EA becomes, the stronger the ability to receive the electronic have [54]. Therefore, TY6 has a higher ability to accept electrons. In solvent, the IP ordering of the three molecules is consistent with that in gas, and each 

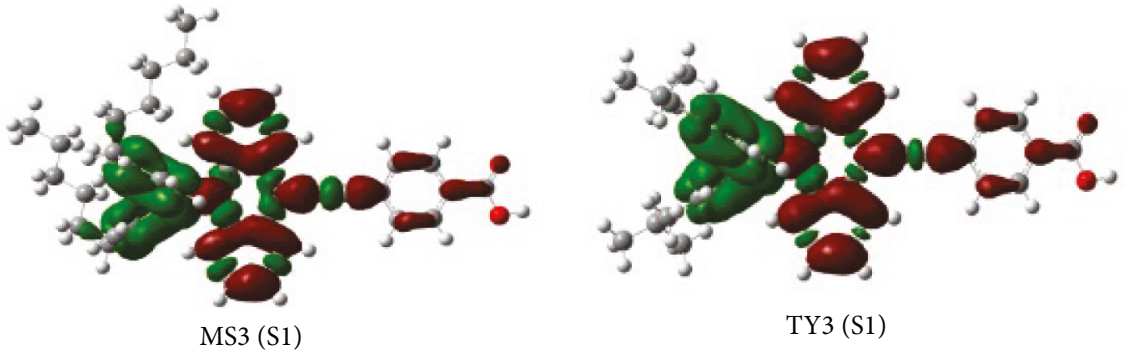

TY3 (S1)
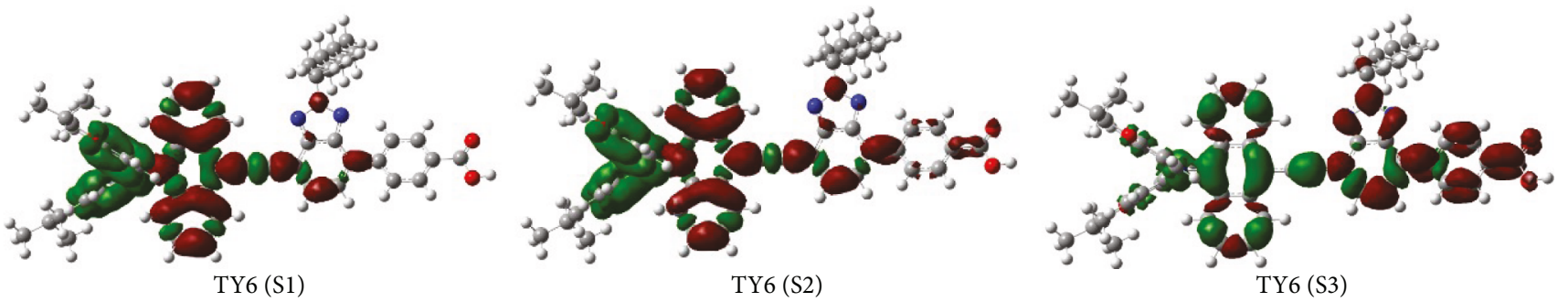

FIGURE 3: The charge difference density (CDD) for MS3, TY3, and TY6 in solvent (green and red stand for the hole and electron, respectively).
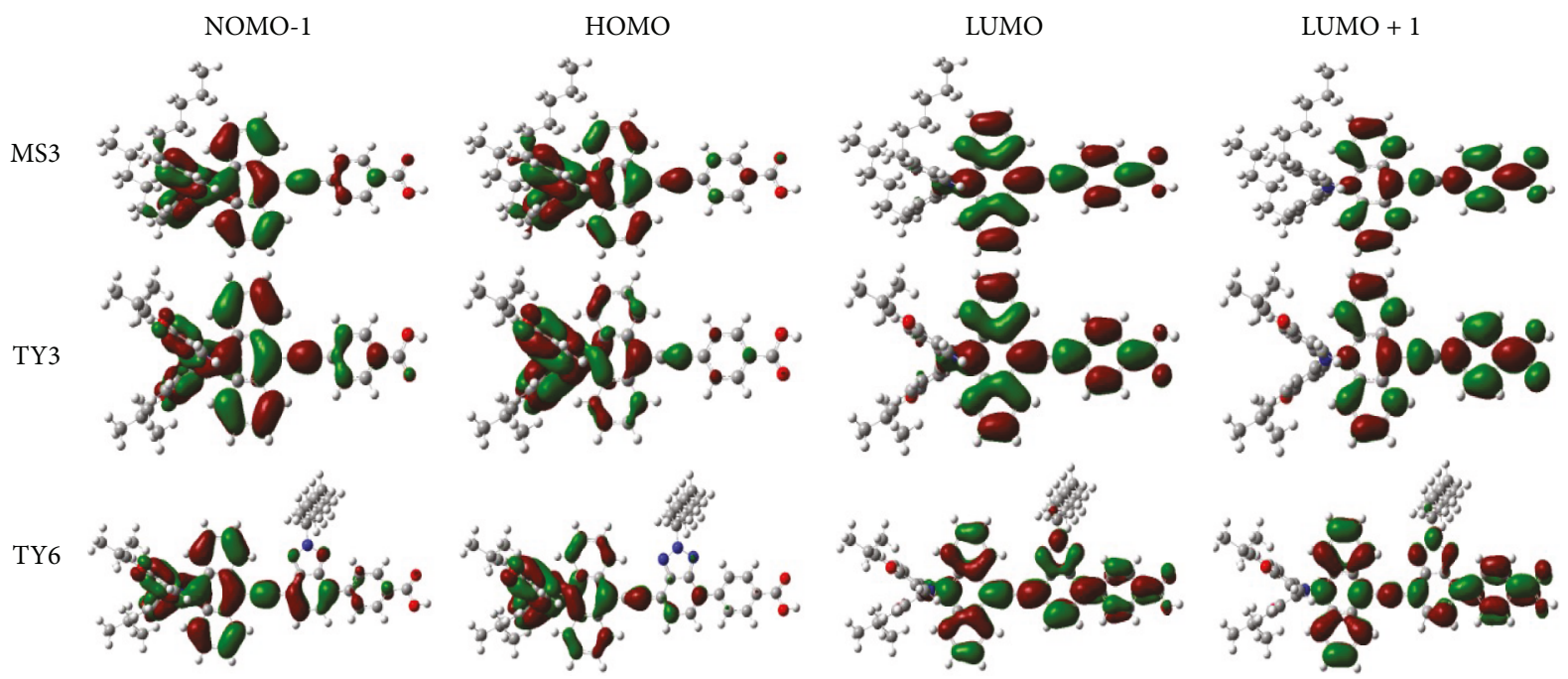

Figure 4: Frontier molecular orbitals of MS3, TY3, and TY6.

molecule decreases by about $0.9 \mathrm{eV}$. At the same time, EA increased by $1.2 \mathrm{eV}$ compared with the gas phase. In general, the effect in solvent is better than that in gas. It is obvious that the electron transport performance of TY6 is better than that of TY3 and MS3.

Table 5 lists the chemical hardness $(h)$, electrophilicity $(\omega)$, and electroaccepting power $\left(\omega^{+}\right) . h$ represents the strength of resistance to ICT $[55,56]$; a small $h$ is helpful in reducing resistance to ICT. $\omega^{+}$represents the higher ability to accept electronics [57]. Many studies have shown that lower $h$ and higher $\omega^{+}$can lead to higher short-circuit currents. In gas, $h$ is arranged in the order MS3 $(3.62 \mathrm{eV})>$ TY 6 $(3.44 \mathrm{eV})>\mathrm{TY} 3(3.43 \mathrm{eV}) ; \omega^{+}$is arranged in the following order: TY6 $(1.43 \mathrm{eV})>\mathrm{MS} 3(1.35 \mathrm{eV})>\mathrm{TY} 3(1.22 \mathrm{eV})$. There was no significant difference between TY3 $(3.43 \mathrm{eV})$ and TY6 $(3.44 \mathrm{eV})$ in $h$. However, TY6 $(1.43 \mathrm{eV})$ was significantly higher than MS3 $(1.35 \mathrm{eV})$ in terms of $\omega^{+}$. In solvent, the orders of $h$ and $\omega^{+}$are the same as those in the gas phase. However, $\omega^{+}$has a significant improvement, and MS3 increases by $2.75 \mathrm{eV}$, TY3 increases by $2.69 \mathrm{eV}$, and TY6 increases by $3.30 \mathrm{eV}$. The promotion of TY6 is the most obvious, and it represents a higher receiving capacity. $\omega$ represents the stability of the dye molecule system [58]. In gas, $\omega$ is arranged in the following order: TY6 $(2.89 \mathrm{eV})>\mathrm{MS} 3$ $(2.87 \mathrm{eV})>$ TY3 $(2.66 \mathrm{eV})$. In solvent conditions, MS3 increased by $2.94 \mathrm{eV}$, TY3 increased by $2.90 \mathrm{eV}$, and TY6 increased by $3.53 \mathrm{eV}$. It is clear that TY6 has not only the highest $\omega$ but also the highest increase in solvent. Therefore, TY6 has the highest energetic stability.

3.5. Performance of DSSCs Based on Dyes. Normally, the photoelectric energy conversion efficiency of DSSCs is mainly affected by open-circuit photovoltage $\left(V_{\mathrm{OC}}\right)$, shortcircuit current density $\left(J_{\mathrm{SC}}\right)$, fill factor $(\mathrm{FF})$, and total 


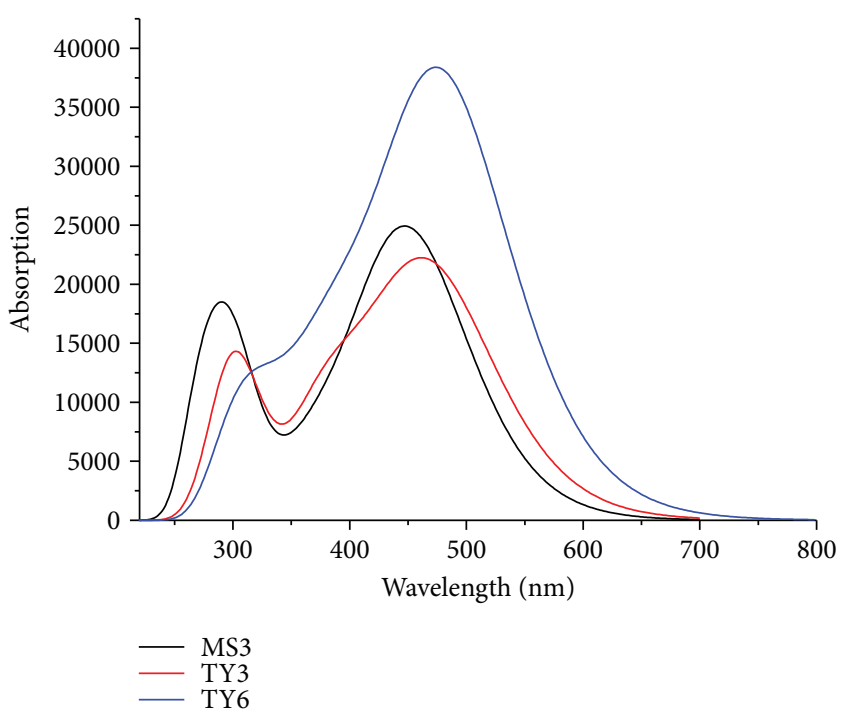

(a)

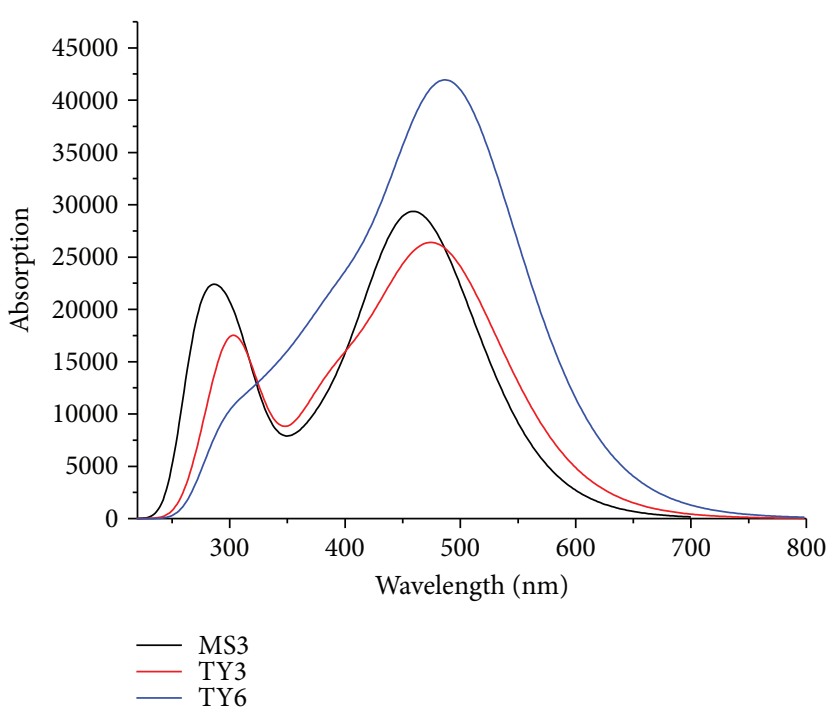

(b)

Figure 5: (a) The UV-Vis absorption spectra in gas and (b) the UV-Vis absorption spectra in solvent.

TABLE 4: Ionization potentials (IP) and electron affinities (EA) of three original molecules in gas and solvent (in $\mathrm{eV}$ ).

\begin{tabular}{lcccc}
\hline & & MS3 & TY3 & TY6 \\
\hline \multirow{2}{*}{ Gas } & IP & 5.89 & 5.65 & 5.49 \\
& EA & 1.34 & 1.22 & 1.40 \\
\hline \multirow{2}{*}{ Solvent } & IP & 4.94 & 4.74 & 4.70 \\
& EA & 2.54 & 2.43 & 2.62 \\
\hline
\end{tabular}

TABle 5: Chemical reactivity parameters (in eV) of MS3, TY3, and TY6 in gas and solvent, respectively.

\begin{tabular}{lcccccc}
\hline & \multicolumn{2}{c}{ MS3 } & \multicolumn{2}{c}{ TY3 } & \multicolumn{2}{c}{ TY6 } \\
& Gas & Solvent & Gas & Solvent & Gas & Solvent \\
\hline$h$ & 3.62 & 3.74 & 3.43 & 3.58 & 3.44 & 3.66 \\
$\omega^{+}$ & 1.35 & 4.10 & 1.22 & 3.91 & 1.43 & 4.73 \\
$\omega$ & 2.87 & 5.81 & 2.66 & 5.56 & 2.89 & 6.42 \\
\hline
\end{tabular}

incident solar energy $\left(P_{\text {in }}\right)$. Calculated efficiency can be written as follows [59]:

$$
\eta=\mathrm{FF} \frac{V_{\mathrm{OC}} J_{\mathrm{SC}}}{P_{\mathrm{in}}} \times 100 \%
$$

From the formula, it can be seen that high $V_{\mathrm{OC}}$ and $J_{\mathrm{SC}}$ are the basis for producing photoelectric conversion efficiency. The $J_{\mathrm{SC}}$ in DSSCs can be calculated by the following equation:

$$
J_{\text {SC }}=\int_{\lambda} \operatorname{LHE}(\lambda) \Phi_{\text {inject }} \eta_{\text {collect }}(d \lambda),
$$

where $\operatorname{LHE}(\lambda)$ is a light harvesting efficiency at maximum wavelength, $\Phi_{\text {inject }}$ is defined as the dye molecule exciting
TABLE 6: The electron injection and regeneration free energy, the light harvesting efficiency (LHE) and lifetime $(t)$.

\begin{tabular}{lccccccc}
\hline & & $\Delta G^{\text {inject }}$ & $\Delta G_{\text {dye }}^{\text {regen }}$ & $E_{\text {OX }}^{\text {dye }}$ & $E_{\text {OX }}^{\text {dye }}$ & LHE & $t(\mathrm{~ns})$ \\
\hline \multirow{4}{*}{ Gas } & MS3 & -1.84 & -0.06 & 4.91 & 2.16 & 0.742 & 5.20 \\
& TY3 & -1.97 & 0.18 & 4.67 & 2.03 & 0.692 & 6.48 \\
& TY6 & -1.99 & 0.26 & 4.59 & 2.01 & 0.871 & 3.91 \\
\hline \multirow{4}{*}{ Solvent } & MS3 & -1.67 & -0.16 & 5.01 & 2.33 & 0.801 & 4.57 \\
& TY3 & -1.77 & 0.04 & 4.80 & 2.23 & 0.759 & 5.60 \\
& TY6 & -1.74 & 0.08 & 4.77 & 2.26 & 0.895 & 3.73 \\
\hline
\end{tabular}

electron injection efficiency, and $\eta_{\text {collect }}$ is the charge collection efficiency. LHE can be expressed as [60]

$$
\text { LHE }=1-10^{-f},
$$

where $f$ is the oscillator strength of the dye molecules; a large oscillator strength can contribute to the improvement of LHE. The electron injection-free energy $\left(\Delta G^{\text {inject }}\right)$ can be represented as [61]

$$
\Delta G_{\text {inject }}=E_{\mathrm{OX}}^{\mathrm{dye} *}-E_{\mathrm{CB}} .
$$

$E_{\mathrm{CB}}$ is the reduction potential of the $\mathrm{TiO}_{2}$ semiconductor and is equal to $4.0 \mathrm{eV}$ [62] (versus vacuum) in this work. $E_{\mathrm{OX}}^{\text {dye* }}$ is the oxidation reduction potential of the dye in the excited state. $E_{\mathrm{OX}}^{\text {dye* }}$ can be expressed as [63]

$$
E_{\mathrm{OX}}^{\mathrm{dye} *}=E_{\mathrm{OX}}^{\mathrm{dye}}-E_{00}
$$

where $E_{\mathrm{OX}}^{\text {dye }}$ is the oxidation potential energy of the dye in the ground state, while $E_{00}$ is the electronic vertical transition energy corresponding to $\lambda_{\max }$.

The calculated values of LHE and $\Delta G^{\text {inject }}$ are listed in Table 6. $\Delta G^{\text {inject }}$ is an important factor affecting the electron 

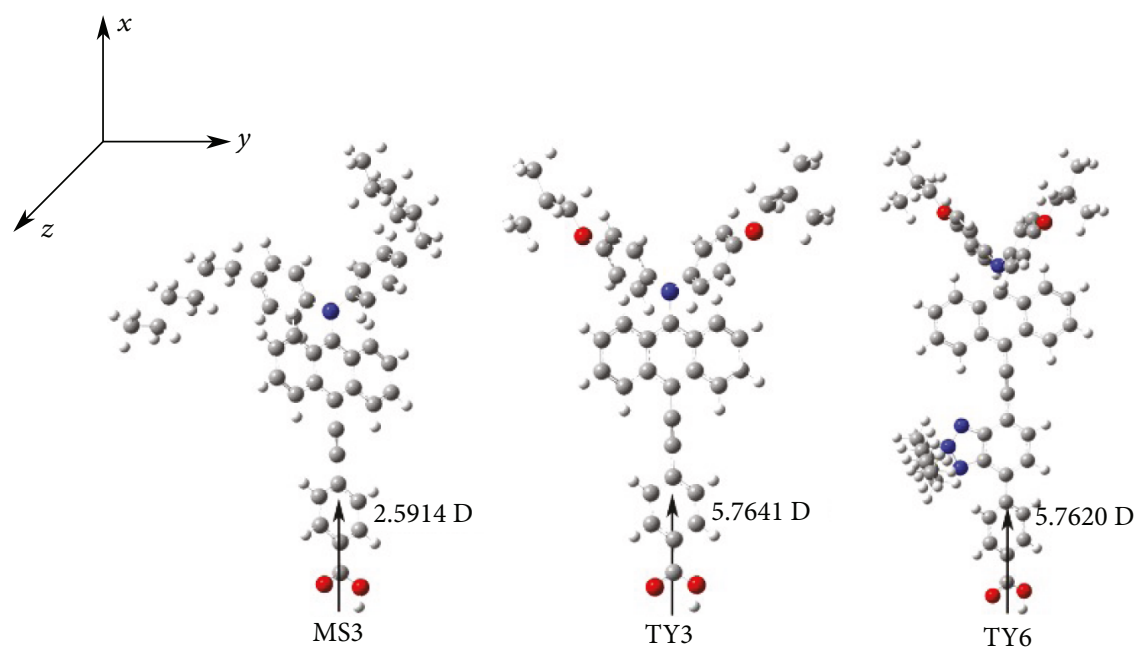

FIgURE 6: Calculated vertical dipole moment $\mu_{\text {normal }}\left(10^{-30} \mathrm{C} \cdot \mathrm{m}\right)$ of MS3, TY3, and TY6 in solvent.

injection rate. In gas conditions, the $\Delta G^{\text {inject }}$ values of MS3, TY3, and TY6 are $-1.83,-1.97$, and $-1.99 \mathrm{eV}$, respectively. Because $\Delta G^{\text {inject }}$ is negative, upon excitation of the molecule by light, electrons can be injected into $\mathrm{TiO}_{2}$ more quickly. Higher LUMO can lead to a higher $\Delta G^{\text {inject }}$ (absolute value). As shown in Table 2, LUMO of TY3 $(-2.26 \mathrm{eV})$ and TY6 $(-2.30 \mathrm{eV})$ is higher than that of MS3 $(-2.33 \mathrm{eV})$. The corresponding $\Delta G^{\text {inject }}$ is higher than that of MS3. Therefore, the improvement in DSSC's PCE is due to the high $\Delta G^{\text {inject }}$, further resulting in high electron injection efficiency. The higher $\Delta G^{\text {inject }}$ is good for increasing the $J_{\text {SC }}$ of the DSSC. In solvent conditions, $\Delta G^{\text {inject }}$ has a small change. However, TY6 still has the highest $\Delta G^{\text {inject }}$ (absolute value). To sum up, TY6 will have higher $J_{\mathrm{SC}}$. Three molecules of light harvesting efficiency can be obtained from Table 6 . In gas, the data is sorted in the order TY6 (0.871) > MS3 (0.742) > TY3 (0.692). The introduction of the side chains on BTZ will increase LHE, and a larger oscillator strength will lead to a higher LHE. From Table 3, it can be found that the oscillator strength of the three molecules in solvent was higher than that in gas. So the LHE in solvent is greatly improved, and TY6 (0.895) still has the highest LHE. Therefore, under the excitation of light, TY6 has higher solar light utilization, producing more photocurrent, and this result indicates that TY6 will have higher $J_{\mathrm{SC}}$. Dye regeneration free energy $\left(\Delta G_{\text {dye }}^{\text {regen }}\right)$ is a significant factor affecting photoelectric conversion efficiency which can be written as follows [64]:

$$
\Delta G_{\text {dye }}^{\text {regen }}=E_{\text {redox }}^{\text {electrolyte }}-E_{\mathrm{OX}}^{\text {dye }}
$$

where $E_{\text {redox }}^{\text {electrolyte }}$ is the redox potential of $I^{-} / I_{3}^{-}(-4.85 \mathrm{eV})$ [65]. Table 6 shows $\Delta G_{\text {dye }}^{\text {regen }}$ of three molecules. In gas conditions, the data is sorted in the order TY6 $(0.26 \mathrm{eV})>\mathrm{TY} 3$ $(0.18 \mathrm{eV})>\mathrm{MS} 3 \quad(-0.06 \mathrm{eV})$. In solvent conditions, the decrease in HOMO results in the increase in $\Delta G_{\text {dye }}^{\text {regen }}$ (see Table 2). So, it has a great influence on TY6, which has the largest $\Delta G_{\text {dye }}^{\text {regen }}(0.08 \mathrm{eV})$. The larger $\Delta G_{\text {dye }}^{\text {regen }}$ can promote dye regeneration and increase $J_{\text {SC }}$. This means that TY6 will have a better performance.

Another important factor affecting the efficiency of electron transfer is the lifetime $(t)$ of the first excited state. If the molecule has a longer life span, it will contribute to the charge transfer of the molecule [66]. The lifetime $(t)$ can be obtained by the latter formula: $t=1.499 /\left(f E^{2}\right)$, where $f$ is the oscillator strength and $E\left(\mathrm{~cm}^{-1}\right)$ is the excitation energy of the different electronic states [67]. Table 6 shows the corresponding data, and the result in the gas phase is in the order TY3 $(6.48 \mathrm{~ns})>\mathrm{MS} 3$ (5.20 ns) > TY6 (3.91 ns). In solvent, the order does not change, but the gap of them decreases. TY6 has a lower $t$, which is owing to the fact that TY6 has a very high $f$ (Table 3 ). As known, there are many complicated factors that affect $J_{\mathrm{SC}}$. According to (5), although TY6 has a lower $t$, it has the highest LHE and $\Delta$ $G^{\text {inject }}$, and it does not affect the highest $J_{\mathrm{SC}}$. As for $V_{\mathrm{OC}}$ in DSSCs, it is described by [68]

$$
V_{\mathrm{OC}}=\frac{E_{\mathrm{CB}}}{q}+\frac{\mathrm{KT}}{q} \operatorname{In} \frac{n_{c}}{N_{\mathrm{CB}}}-\frac{E_{\mathrm{redox}}}{q} .
$$

Here, $E_{\mathrm{CB}}$ is the conduction band edge of $\mathrm{TiO}_{2}, q$ is the unit charge, $\mathrm{KT}$ is the thermal energy, $n_{c}$ is the number of electrons in the $\mathrm{CB}, N_{\mathrm{CB}}$ is the accessible density of $\mathrm{CB}$ states, and $E_{\text {redox }}$ is the redox potential of the electrolyte. Equation (7) shows that the energy $E_{\mathrm{CB}}$ and the number of electrons in the $\mathrm{CB}$ are important factors affecting $V_{\mathrm{OC}} \cdot \Delta E_{\mathrm{CB}}$ is the displacement of $\mathrm{CB}$ when the dye absorbs on the surface of $\mathrm{TiO}_{2}$, which can be expressed as [69]

$$
\Delta E_{\mathrm{CB}}=\frac{q \mu_{\text {normal }} \gamma}{\varepsilon \varepsilon_{0}}
$$

$\gamma$ is the concentration of dyes in the surface, $\mu_{\text {normal }}$ is the dipole moment component perpendicular to the direction of the $\mathrm{TiO}_{2}$ surface (where $\mu_{\text {normal }}$ is the $x$-axis direction), $\varepsilon$ is the dielectric constant of the organic monolayer, and $\varepsilon_{0}$ is the dielectric constant of the vacuum. Figure 6 shows the values of the vertical dipole moment $\left(\mu_{\text {normal }}\right)$. TY3 (5.7641 D) 
TABLE 7: Natural bond orbital analysis for the ground state (S0) and excited state (S1) of the dyes.

\begin{tabular}{cccccc}
\hline Dye & & Donor & Anthracene & $\pi$ & Acceptor \\
\hline \multirow{4}{*}{ Ms3 } & S0 & -0.1002 & 0.1376 & 0.0099 & -0.0473 \\
& S1 & 0.1806 & -0.0839 & -0.0005 & -0.0963 \\
& $\Delta_{q}$ & -0.2808 & 0.2215 & 0.0104 & 0.0490 \\
\hline \multirow{4}{*}{ TY3 } & S0 & 0.3139 & 0.1368 & 0.0099 & -0.0433 \\
& S1 & 0.6290 & -0.1882 & -0.0091 & -0.1050 \\
& $\Delta_{q}$ & -0.3151 & 0.3250 & 0.0190 & 0.0617 \\
\hline \multirow{4}{*}{ TY6 } & S0 & -0.0947 & 0.1486 & 0.0258 & -0.0796 \\
& S1 & 0.1802 & -0.0528 & 0.0155 & -0.1429 \\
& $\Delta_{q}$ & -0.2749 & 0.2014 & 0.0103 & 0.0633 \\
\hline
\end{tabular}

and TY6 (5.7620 D) has a similar value. Compared with MS3 (2.5914 D), TY3 and TY6 have more $\mu_{\text {normal }}$. We optimized the donor moiety through changing the C-6 alkyl chain of MS3 to the branched carbon alkoxy group, which proves that the change in the donor portion can improve the vertical dipole moment of dye molecules effectively. Meanwhile, it cause the nanocrystalline semiconductor conduction band $E_{\mathrm{CB}}$ mobile to the positive direction of $\mathrm{x}$-axis, and then improve $V_{O C}$.

3.6. Natural Bond Orbital Analysis. In order to understand the mechanism of photoexcitation, we simulated the natural bond orbital $(\mathrm{NBO})$ of the optimized structure of the ground state (S0) and the first excited state (S1) of MS3, TY3, and TY6. The acceptor of TY6 includes benzoic acid and the auxiliary acceptor (BTZ group), and the detailed data is listed in Table 7. The amount of charge difference $\left(\Delta_{q}\right)$ from S0 to S1 in the donor group shows that TY3 $(-0.3151)$ can contribute more electrons compared to MS3 $(-0.2808)$ and TY3 $(-0.2749)$. But $\Delta_{q}$ in the anthracene group and acceptor groups shows that more of the contributing electrons in TY3 are concentrated in the anthracene group. So, only a small amount of electrons reach the acceptor part in TY3. Eventually, the acceptor group of TY6 has more electrons. It showed that the auxiliary acceptor (BTZ) in TY6 increased the total amount of electron in the acceptor. At the same time, $\Delta_{q}$ of MS3 (0.0104), TY3 (0.0190), and TY6 $(0.0103)$ in the $\pi$ region indicates that the $\pi$-linker is only a channel for the charge transfer. To sum up, TY6 can provide more efficient excitation electrons in the photoexcitation mechanism.

3.7. Hyperpolarizabilities and Reorganization Energies. The total static first hyperpolarisability can be expressed as [70]

$$
\beta_{\mathrm{tot}}=\sqrt{\beta_{x}^{2}+\beta_{y}^{2}+\beta_{z}^{2}} .
$$

The static component is calculated by the following equation:

$$
\beta_{i}=\beta_{i i i}+\frac{1}{3} \sum_{i \neq j}\left(\beta_{i j i}+\beta_{j i j}+\beta_{j j i}\right)
$$

where $\beta_{i j k}(i, j, k=x, y, z)$ are tenser components of hyperpolarizability. Finally, the equation is written as

$$
\begin{aligned}
\beta_{\text {tot }}=[ & \left(\beta_{x x x}+\beta_{x y y}+\beta_{x z z}\right)^{2}+\left(\beta_{y y y}+\beta_{y z z}+\beta_{y x x}\right)^{2} \\
& \left.+\left(\beta_{z z z}+\beta_{z x x}+\beta_{z y y}\right)^{2}\right]^{1 / 2} .
\end{aligned}
$$

For DSSCs, the ICT process facilitates the aggregation of electrons in the acceptor moiety, and the enhanced electron density in the acceptor moiety can enhance the electronic coupling effect between acceptor and semiconductor. The first $\beta$ is directly proportional to the transition dipole moment ((oscillator strength) $\left.\left(\mu_{\mathrm{eg}}\right)\right)$ and the difference in the dipole moment between the ground and excited orbitals $\left(\Delta \mu_{\mathrm{eg}}\right)$, and it is inversely proportional to the transition energy $\left(E_{\text {eg }}\right)$. $\beta$ can be expressed as follows [71]:

$$
\beta \propto \frac{\Delta \mu_{\mathrm{eg}}\left(\mu_{\mathrm{eg}}\right)^{2}}{E_{\mathrm{eg}}^{2}},
$$

where $\Delta \mu_{\mathrm{eg}}$ and $\mu_{\mathrm{eg}}$ are difference in the dipole moment for ground state and excited state, and the transition dipole, $E_{\mathrm{eg}}$, is the transition energy. The first hyperpolarizabilities are listed in Table 8. $\beta_{x x x}$ (along the coordinate axis of the molecule) is a negative value, and the negative charge is far away from the nuclear charge of the molecule. $\beta_{\text {tot }}$ of TY6 is much larger than MS3 and TY3 values. Table 3 and Figure 6 support the results of hyperpolarizabilities. Figure 6 shows that TY3 and TY6 have higher dipole moments, and TY6 has higher oscillator strengths (in Table 3); so, TY6 has a higher $\mu_{\mathrm{eg}}$. At the same time, TY6 has less excitation energy in Table 2. So, TY6 has larger hyperpolarizabilities with an obvious charge transfer.

The reorganization energy can affect CT, which is more beneficial to the improvement of CT [72]. On the basis of the Marcus theory, CT can be calculated by [73]

$$
K_{\mathrm{ET}}=A \exp \left[\frac{-\lambda}{4 K_{\mathrm{B}} T}\right],
$$

where $\lambda$ is the reorganization energy, $A$ is the electronic coupling, $K_{\mathrm{B}}$ is the Boltzmann constant, and $T$ is the temperature. Hole or electron reorganization energy is determined by the following equation [74]:

$$
\begin{aligned}
& \lambda_{h}=\left(E_{0}^{-}-E_{-}\right)+\left(E_{-}^{0}-E_{0}\right), \\
& \lambda_{e}=\left(E_{0}^{+}-E_{+}\right)+\left(E_{+}^{0}-E_{0}\right),
\end{aligned}
$$

where $E_{-}^{0}\left(E_{0}^{+}\right)$represents the energy of the neutral molecule calculated at the anionic (cationic) state. $E_{0}^{-}\left(E_{0}^{+}\right)$represents the anion (cation) energy calculated with the optimized structure of the neutral molecule. $E_{-}\left(E_{+}\right)$represents the anion (cation) energy calculated with the optimized anion (cation) structure. $E_{0}$ represents the energy at the neutral molecule at the ground state. $\lambda_{h}, \lambda_{e}$, and $\lambda_{\text {total }}$ values are listed in Table 9. In the gas phase, the $\lambda_{h} / \lambda_{e}$ values of MS3, TY3, 
TABLE 8: Hyperpolarizabilities of MS3, TY3, and TY6 in the gas phase.

\begin{tabular}{lcccccccccccc}
\hline Gas & $\beta_{x x x}$ & $\beta_{x x y}$ & $\beta_{x y y}$ & $\beta_{y y y}$ & $\beta_{x x z}$ & $\beta_{x y z}$ & $\beta_{y y z}$ & $\beta_{x z z}$ & $\beta_{y z z}$ & $\beta_{z z z}$ & $\beta_{\text {tot }}$ & $\beta_{x y y}$ \\
\hline MS3 & 221,672 & -0.5 & $-11,899$ & 881 & $-39,351$ & 35 & 1874 & 5715 & -14 & -934 & 218,887 & $-11,899$ \\
TY3 & $-236,112$ & 8336 & 7172 & 2538 & 8946 & -50 & 72 & 933 & 18 & 661 & 228,473 & 7172 \\
TY6 & 754,632 & 7313 & -8155 & 3421 & 32,781 & 322 & -420 & -97 & 24 & -1037 & 747,115 & -8155 \\
\hline
\end{tabular}

TABLE 9: Reorganization energy of MS3, TY3, and TY6 in gas and solvent phases.

\begin{tabular}{lcccc}
\hline & & MS3 & TY3 & TY6 \\
\hline \multirow{3}{*}{ Gas } & $\lambda_{h}$ & 0.18 & 0.21 & 0.20 \\
& $\lambda_{e}$ & 0.27 & 0.33 & 0.33 \\
& $\lambda_{\text {total }}$ & 0.45 & 0.54 & 0.53 \\
\multirow{3}{*}{ Solvent } & $\lambda_{h}$ & 0.17 & 0.19 & 0.17 \\
& $\lambda_{e}$ & 0.23 & 0.25 & 0.25 \\
& $\lambda_{\text {total }}$ & 0.40 & 0.44 & 0.42 \\
\hline
\end{tabular}

and TY6 are $0.18 / 0.27,0.21 / 0.33$, and $0.20 / 0.33$. The $\lambda_{\text {total }}$ values of the three molecules are in the order TY3 $(0.54 \mathrm{eV})>$ TY6 $(0.53 \mathrm{eV})>$ MS3 $(0.45 \mathrm{eV})$. The results show that the $\lambda_{h}$ values of three molecules are lower than those of $\lambda_{e}$, which indicates that the electron transfer rate is lower than the hole transfer rate. Obviously, MS3 has a higher hole and electron transfer rate, followed by TY6. From the gas phase to solvent, $\lambda_{h}$ and $\lambda_{e}$ have decreased. For $\lambda_{\text {total }}$, MS3, TY3, and TY6 are reduced to be $0.05 \mathrm{eV}, 0.10 \mathrm{eV}$, and $0.11 \mathrm{eV}$ (see Table 9). The above data shows that values of $\lambda_{h}$ and $\lambda_{e}$ have been reduced in the THF solvent. TY6 has the greatest reduction in solvent and is very close to MS3 $(0.40 \mathrm{eV})$. As a result, MS3 and TY6 will lead to better hole/ electron transport and efficient luminescent materials.

3.8. Analysis of Electrostatic Potential Distribution on the Molecular Surface. In order to determine the position of electrolyte ions, we can determine the reactive sites of dye molecules by the molecular surface electrostatic potential (ESP) [75]. The ESP of three molecules is listed in Figure 7(a) (the detailed values are marked). The red point represents the maximum point of the electrostatic potential of the molecular surface, and the blue point represents the minimum point of the electrostatic potential of the molecular surface. For the three molecules, the maximum values of the electrostatic potential on the molecular surface are distributed near the $\mathrm{H}$ atom of the acceptor, and the specific values are as follows: MS3 $(53.56 \mathrm{kcal} / \mathrm{mol})$, TY3 $(52.61 \mathrm{kcal} / \mathrm{mol})$, and TY6 $(51.55 \mathrm{kcal} / \mathrm{mol})$. It shows that the acceptor $\mathrm{H}$ atom is positively charged, which means that it has the most powerful ability to attract nucleophiles and is the most likely place to gather negative charges together. At the same time, the minimum values of electrostatic potential on the surface of molecules are distributed near the acceptor $\mathrm{O}$ atom, and the specific data are as follows: MS3 $(-37.62 \mathrm{kcal} / \mathrm{mol})$, TY3 $(-38.43 \mathrm{kcal} / \mathrm{mol})$, and TY6 $(-39.81 \mathrm{kcal} / \mathrm{mol})$. This indicates that the lone pair electrons of the acceptor $\mathrm{O}$ atom negatively contribute to the electrostatic potential, and its position implies the ability to attract the electric reagents strongly, which is most likely to gather the position of positive charge together. By electrostatic interactions, it is possible to infer that the positions of $\mathrm{O}$ and $\mathrm{H}$ atoms of the three molecular acceptors are the most active regions of the molecular reactions.

In order to show the molecular surface area of different electrostatic potential intervals, the quantitative distribution chart of the electrostatic potential on the surface of molecules is plotted, which is listed in Figure 7(b). As shown, the distribution of the surface electrostatic potential at the maximum and minimum points of the three molecules is very small in this region. The electrostatic potential area of the larger region is as follows: MS3 $(-17.83,13.83 \mathrm{kcal} / \mathrm{mol})$, TY3 $(-18.07,13.27 \mathrm{kcal} / \mathrm{mol})$, and TY6 $(-24.67,18.27 \mathrm{kcal} / \mathrm{mol})$. It seems that the electrostatic potential distribution of TY6 is wider and more homogeneous than that of MS3 and TY3. Therefore, the surface reaction region of TY6 is the largest, and the overall reaction activity is stronger.

3.9. Molecular Design. After the above discussion, the TY6 molecule has the best photoelectric conversion efficiency. On the basis of this molecule, a series of molecules were designed by inserting different electron-withdrawing groups (EWGs $\left(-\mathrm{CF}_{3}(\mathrm{~A}),-\mathrm{CN}(\mathrm{B})\right.$, and $\left.-\mathrm{F}(\mathrm{C})\right)$ ) into number 1 , 2,3 , and 4 positions of the original molecule acceptor, respectively. The designed molecular structures are shown in Figure 8 , and those dyes are named as TY6-X $(\mathrm{X}=1 \mathrm{~A}, 2 \mathrm{~A}$, $3 \mathrm{~A}, 4 \mathrm{~A}, 1 \mathrm{~B}, \ldots, 4 \mathrm{C})$. The following calculation results are obtained in the gas phase. The calculated bond lengths and dihedral angle are listed in Table 10. The dihedral angle ( $\angle \mathrm{C} 1-\mathrm{C} 2-\mathrm{N} 3-\mathrm{C} 4$ and $\angle \mathrm{C} 2-\mathrm{N} 3-\mathrm{C} 4-\mathrm{C} 5)$ on the donor is not significantly changed compared with the original molecule, and bond length has almost no change. However, the dihedral angle ( $\angle \mathrm{C} 6-\mathrm{C} 7-\mathrm{C} 8-\mathrm{C} 9)$ of the acceptor is changed obviously, and the change of the molecule with the insertion of the $-\mathrm{CN}$ group has the largest change. It is worth noting that the dihedral angles of TY6-1X and TY6-4X ( $\angle$ C6-C7-C8-C9) have a significant increase, while TY6-2X and TY6-3X have no significant changes. It is due to the fact that the close distance between the introduction of EWGs and the long alkyl chain introduced on BTZ will result in mutual exclusion, and TY6-1X $(\mathrm{X}=\mathrm{A}, \mathrm{B}, \mathrm{C}, \mathrm{D})$ is larger than TY6-4X $(\mathrm{X}=\mathrm{A}$, $\mathrm{B}, \mathrm{C}, \mathrm{D})$. For example, the dihedral angles of TY6-1A and TY6-4A are $65.82^{\circ}$ and $49.99^{\circ}$, respectively. The twisted structure of the donor blocks the movement of electrons on the donor; therefore, TY6-2X and TY6-3X may exhibit a better performance.

The MOs of the designed molecules are shown in Table 11. Compared with the original molecule TY6 
MS3
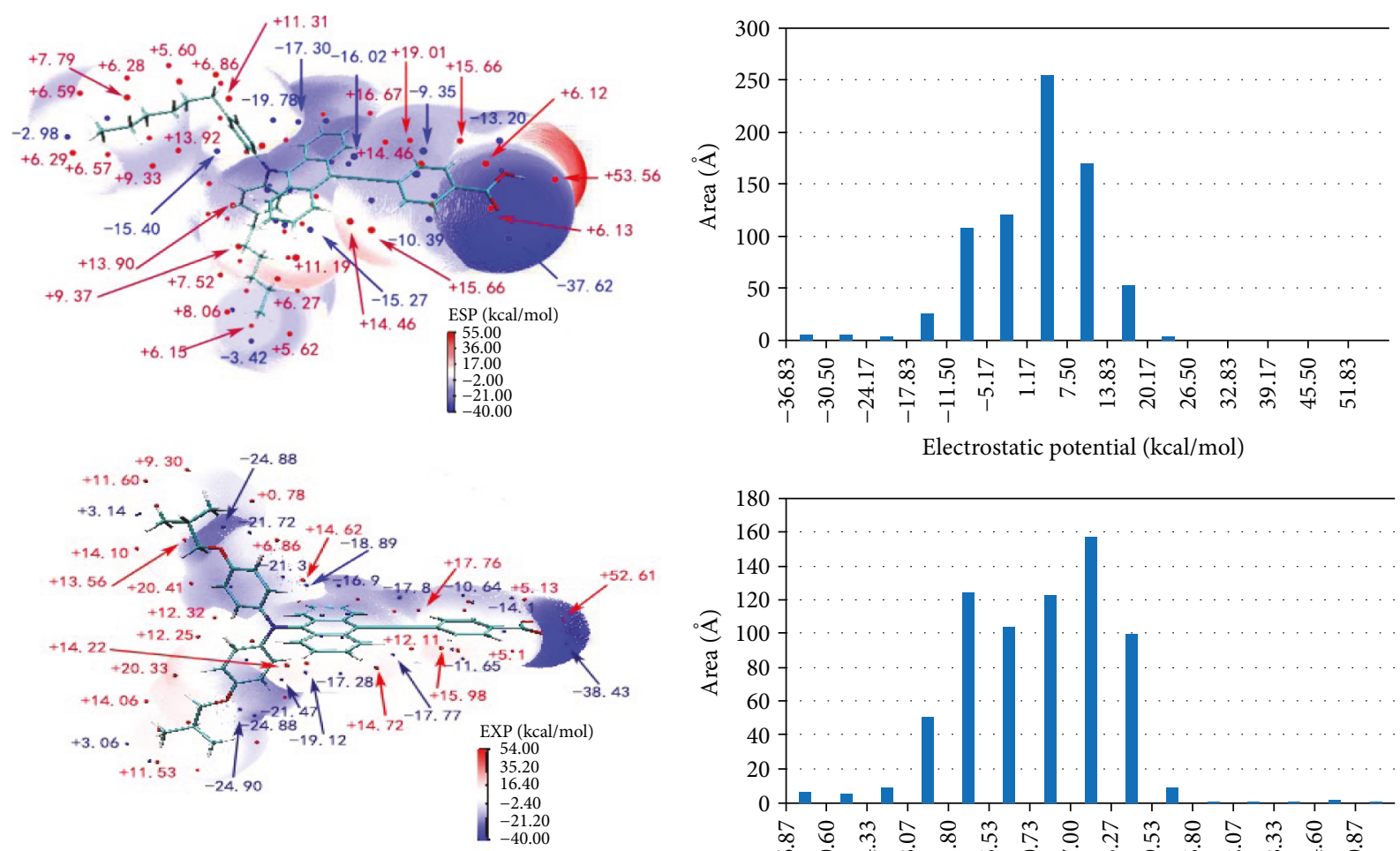

Electrostatic potential $(\mathrm{kcal} / \mathrm{mol})$

TY3

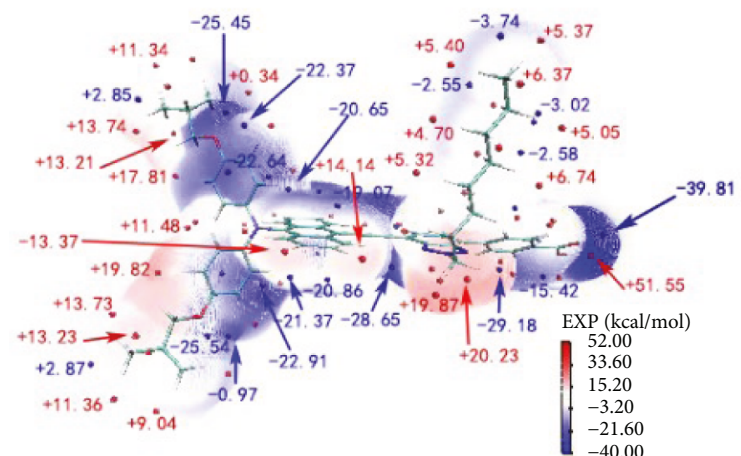

(a)

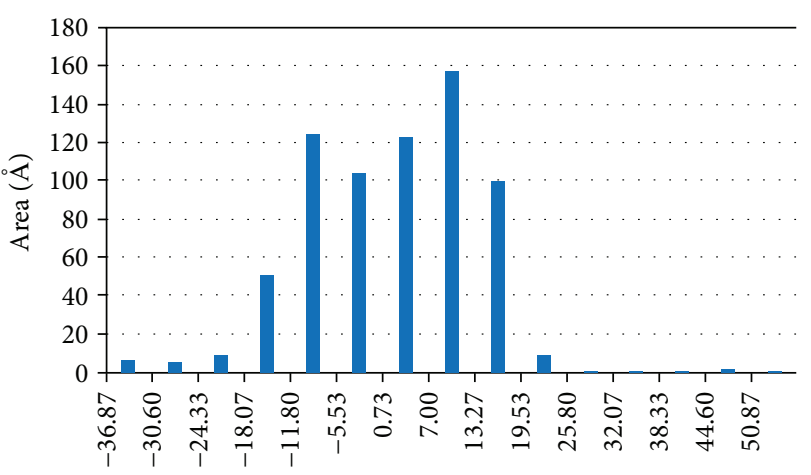

Electrostatic potential $(\mathrm{kcal} / \mathrm{mol})$

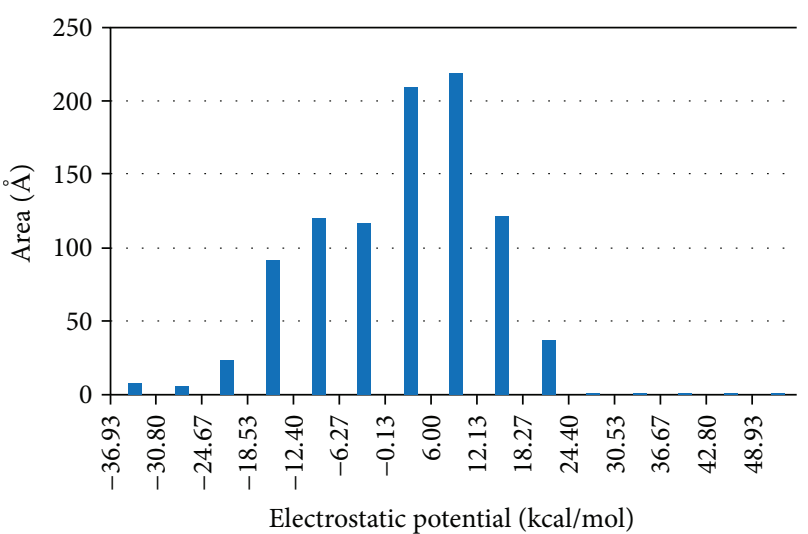

(b)

FIgURE 7: (a) The ESP on the VDW surface of MS3, TY3, and TY6; red and blue points represent maximum and minimum values, respectively. The extrema ESP (in $\mathrm{kcal} / \mathrm{mol}$ ) points on the molecular surface are marked. (b) The molecular surface area of different electrostatic potential interval; the electrostatic potential interval is divided into 15 equal parts.

$(-4.59 \mathrm{eV})$, the HOMO values $(-4.76$ to $-4.58 \mathrm{eV})$ of other design molecules are lower. For instance, the maximum value of $\mathrm{HOMO}$ is $-4.58 \mathrm{eV}$, which adds an $-\mathrm{F} /-\mathrm{CF}_{3}$ group on position 1 of the acceptor (TY6-1C/TY6-1A). The minimum value of $\mathrm{HOMO}$ is $-4.76 \mathrm{eV}$, which adds a $-\mathrm{CF}_{3}$ group on position 3 of the acceptor (TY6-3A). However, for LUMO, most of the designed molecules have a better performance. Compared with the original molecule TY6 $(-2.30 \mathrm{eV})$, the LUMO values $(-2.54$ to $-2.23 \mathrm{eV})$ of the designed molecules are relatively low. The maximum value of LUMO is $-2.23 \mathrm{eV}$, which adds a $-\mathrm{CF}_{3}$ group on position 1 of the acceptor (TY6-1A). The minimum value of LUMO is $-2.54 \mathrm{eV}$, which adds a $-\mathrm{CN}$ group on position $2 / 3$ of the acceptor (TY6-2B/TY6-3B). Compared with the energy gap of the original molecule TY6 $(2.29 \mathrm{eV})$, the design molecules inserted into the $-\mathrm{CN}$ group are all reduced. The minimum energy gap is $2.13 \mathrm{eV}$, which adds a $-\mathrm{CN}$ group on position $2 / 3$ of the acceptor (TY6-2B/TY6-3B). Interestingly, when EWG is inserted into the right side of the acceptor (positions 2 and 3), the energy gap is lower than in other positions. The $-\mathrm{CN}$ group can reduce the molecular LUMO and lead to the decrease in the energy gap. Through the analysis, it can be concluded that the $-\mathrm{CN}$ group is the most conducive to the reduction of the molecular energy gap, followed by 

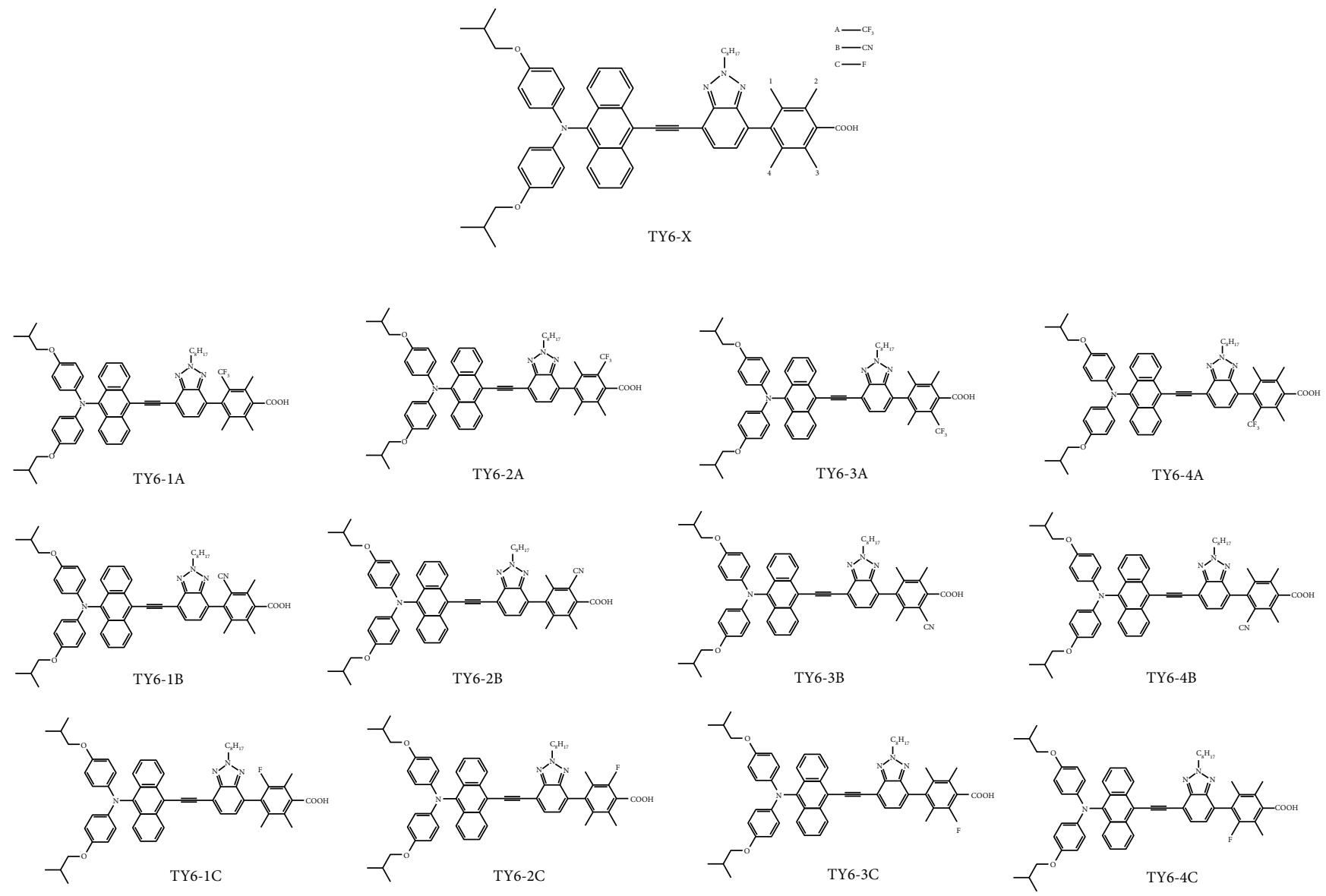

FIgURE 8: Chemical structures of TY6-X and the structure of each designed molecule.

TABLe 10: Selected bond lengths ( $\mathrm{A})$ and dihedral angles $\left({ }^{\circ}\right)$ of TY6 and TY6-X.

\begin{tabular}{lcccccccc}
\hline \multirow{5}{*}{ Dihedral angle } & & TY6 & TY6-1A & TY6-2A & TY6-3A & TY6-4A & TY6-1B & TY6-2B \\
& C1-C2-N3-C4 & 35.20 & 35.30 & 35.24 & 36.69 & 34.88 & 35.38 & 35.63 \\
& C2-N3-C4-C5 & 69.60 & 69.45 & 69.21 & 71.38 & 70.71 & 69.31 & 69.10 \\
& C6-C7-C8-C9 & 29.70 & 65.82 & 26.82 & 29.65 & 49.99 & 55.01 & 26.9 \\
Bond length & C3-C4 & 1.429 & 1.429 & 1.429 & 1.431 & 1.430 & 1.429 & 1.428 \\
& C7-C8 & 1.478 & 1.489 & 1.477 & 1.477 & 1.486 & 1.480 & 1.476 \\
& C10-C11 & 1.483 & 1.487 & 1.493 & 1.496 & 1.486 & 1.487 & 1.486 \\
\hline \multirow{5}{*}{ Dihedral angle } & & TY6-3B & TY6-4B & TY6-1C & TY6-2C & TY6-3C & TY6-4C & 31.12 \\
& C1-C2-N3-C4 & 35.42 & 35.17 & 34.6 & 31.38 & 35.29 & 70.65 \\
Bond length & C6-C7-C8-C9 & 27.65 & 38.33 & 49.15 & 26.70 & 28.43 & 30.95 \\
& C3-C4 & 1.428 & 1.429 & 1.429 & 1.430 & 1.429 & 1.431 \\
& C7-C8 & 1.476 & 1.477 & 1.478 & 1.477 & 1.477 & 1.477 \\
\end{tabular}

the $-\mathrm{CF}_{3}$ group, and least influence corresponding to the $-\mathrm{F}$ group. The electronegativity of the 3 groups increased gradually, which was the same as that of the LUMO. Therefore, the greater the electronegativity of the inserted EWG is, the higher the energy of the LUMO is.

Table 12 lists the oscillator strength and transition energy of the design molecule. The results show a significant change in the absorption properties of the design molecules. For example, compared with TY6 $(481 \mathrm{~nm})$, the maximum absorption peak of the designed molecules has changed significantly. Related data is arranged in the following order: TY6-3B $=$ TY6-2B $>$ TY6-4B $>$ TY6-2A $>$ TY6-3C $>$ TY6- $1 \mathrm{~B}>$ TY6 $>$ TY6- $1 \mathrm{C}>$ TY6- $4 \mathrm{~A}>$ TY6- $2 \mathrm{C}=$ TY6-3A $>$ TY6-1A $>$ TY6-4C. Through the above sorting 
TABLE 11: Frontier molecular orbital energies and energy gaps (eV) of TY6-X.

\begin{tabular}{lcccccc}
\hline & TY6-1A & TY6-2A & TY6-3A & TY6-4A & TY6-1B & TY6-2B \\
H & -4.58 & -4.64 & -4.76 & -4.60 & -4.61 & -4.67 \\
L & -2.23 & -2.43 & -2.45 & -2.31 & -2.38 & -2.54 \\
Gap & 2.35 & 2.21 & 2.31 & 2.29 & 2.23 & 2.13 \\
\hline & TY6-3B & TY6-4B & TY6-1C & TY6-2C & TY6-3C & TY6-4C \\
H & -4.67 & -4.63 & -4.58 & -4.75 & -4.62 & -4.72 \\
L & -2.54 & -2.47 & -2.27 & -2.42 & -2.38 & -2.37 \\
Gap & 2.13 & 2.16 & 2.31 & 2.33 & 2.24 & 2.35 \\
\hline
\end{tabular}

analysis, half of the designed molecules have a red-shifted absorption. Among them, the designed molecules inserted into the $-\mathrm{CN}$ group have an obvious red-shifted absorption, and the maximum value appears in TY6-3B/TY6-2B $(492 \mathrm{~nm})$, which is the insertion of the $-\mathrm{CN}$ group in acceptor position $3 / 2$. As mentioned absove, it seems that there is no obvious regularity change for the insertion of different positions on the acceptor. For insertion of different EWGs, the displacement of the maximum absorption peak of the $-\mathrm{CN}$ group is the most obvious. This is the same characteristic as the low-energy gap, and low LUMO is caused by $-\mathrm{CN}$. Similarly, compared with TY6 (0.8886), the designed molecules have greatly increased the oscillation intensity and are arranged in the following order: TY62C > TY6-4C > TY6-3A $>$ TY6-2B $>$ TY6-3B $>$ TY6-2A $>$ TY6$3 \mathrm{C}>$ TY6-4B $>$ TY6 $>$ TY6-1B $>$ TY6-1C $>$ TY6-4A $>$ TY6- 1 A. As shown, $2 / 3$ of the designed molecules are higher than the original molecules. The maximum value appears in TY6-2C (0.9726), which is the insertion of the $-\mathrm{F}$ group in acceptor position 2 . The minimum value appears in TY6-1A (0.7379), which is the insertion of the $-\mathrm{CF}_{3}$ group in acceptor position 4. It is also found that the designed molecules of the insertion group in acceptor position 1 are less than the original molecules, and the performance is poor. However, the designed molecules inserted at positions 2 and 3 of the acceptor are higher than the original molecules, which shows a better performance. This phenomenon is consistent with the previous conclusions that positions 2 and 3 are better than positions 1 and 4 . Besides, the magnitude of oscillator strength is directly related to the light harvesting efficiency (LHE). It can be seen from Table 13 that the order of the LHE of the designed molecules is consistent with the oscillator strength (TY6, 0.871). What is important is that a higher LHE leads to a better PCE, and it comes to the following conclusion: Molecules with groups inserted at positions 2 and 3 will have a better performance than those at positions 1 and 4 .

Table 13 shows some of the chemical reaction parameters of the design molecules. Compared with the original molecule TY6, most of the designed molecules have significantly increased the values of chemical reaction parameters, and the effect is obvious. For EA, the designed molecules are arranged in the following order: TY6-3B $=$ TY6- $2 \mathrm{~B}=$ TY6-3ATY6$4 \mathrm{~B}>$ TY6-2C > TY6-2A $>$ TY6-4C > TY6-1B > TY6-3C > TY6-
$4 \mathrm{~A}>\mathrm{TY} 6(1.40 \mathrm{eV})>\mathrm{TY} 6-1 \mathrm{~A}>\mathrm{TY} 6-1 \mathrm{C}$. The maximum value of EA appears at TY6-3B/TY6-2B/TY6-3A (1.64 eV), which adds a $-\mathrm{CN} /-\mathrm{CF}_{3}$ group on position $3 / 2$ of the acceptor; the minimum value of EA occurs at TY6-1C $(1.35 \mathrm{eV})$, which adds an $-\mathrm{F}$ group on position 1 of the acceptor. For $\omega^{+}$, the designed molecules are arranged in the following order: TY6-3A $>$ TY6$3 \mathrm{~B}=$ TY6-2B $>$ TY6-2C $=$ TY6- $4 \mathrm{~B}>$ TY6-2A $>$ TY6- $4 \mathrm{C}>$ TY6$1 \mathrm{~B}>$ TY6-3C $>$ TY6- $4 \mathrm{~A}>$ TY6 $(1.43 \mathrm{eV})>$ TY6- $1 \mathrm{~A}>$ TY6-1C. The maximum value of $\omega^{+}$appears at TY6-3A $(1.77 \mathrm{eV})$, which adds a $-\mathrm{CF}_{3}$ group on position 3 of the acceptor; the minimum value of $\omega^{+}$occurs at TY6-1C $(1.37 \mathrm{eV})$, which adds an $-\mathrm{F}$ group on position 1 of the acceptor. For $\omega$, the designed molecules are arranged in the following order: TY6-3B $=$ TY62B $>$ TY6-3A $>$ TY6-4B $>$ TY6-2C > TY6-2A $>$ TY6- 4 C $>$ TY6$1 \mathrm{~B}>$ TY6 3C $>$ TY6 $-4 \mathrm{~A}>$ TY6 $(2.89 \mathrm{eV})>$ TY6 $-1 \mathrm{~A}>$ TY6 $-1 \mathrm{C}$. The maximum value of $\omega$ appears at TY6-3B/TY6-2B $(3.31 \mathrm{eV})$, which adds a $-\mathrm{CN}$ group on position $3 / 2$ of the acceptor; the minimum value of $\omega$ occurs at TY6-1C $(2.83 \mathrm{eV})$, which adds an -F group on position 1 of the acceptor. As mentioned above, we can get some general conclusions as follows. First, for the three kinds of chemical reactivity parameters, the order of the designed molecules is almost consistent, and the order of EA and $\omega$ is exactly the same. Second, the maximum value of the chemical reactivity parameters is found in TY6-3X (position 3 of the acceptor); the corresponding minimum value appears at TY6-1C, and its value is smaller than the original molecular TY6. As a whole, the molecular properties designed at positions 2 and 3 of the acceptor are better than those designed at position 1 and 4 of the acceptor. Finally, all the molecules inserted by the $-\mathrm{CN}$ group showed better performance than the original molecule TY6 did. Furthermore, the introduction of the $-\mathrm{CN}$ group not only can effectively improve the electronic transmission performance and the ability to receive electrons but also can improve the stability of energy.

The total static first hyperpolarizability of the designed molecules is listed in Table 13. Compared with TY6 (747115), the designed molecules have obvious changes and are arranged in the following order: TY6-3B $>$ TY6$1 \mathrm{~B}>$ TY6-2B $>$ TY6-3A $>$ TY6-2A $>$ TY6-1C $>$ TY6-4B $>$ TY6$2 \mathrm{C}>$ TY6-3C $>$ TY6-4C $>$ TY6 $>$ TY6- 1 A $>$ TY6- 4 A. The maximum value of $\beta_{\text {tot }}$ appears at TY6-3B (1068163), which adds a $-\mathrm{CN}$ group on position 3 of the acceptor; the minimum value of $\beta_{\text {tot }}$ occurs at TY6-4A (529611), which adds a $-\mathrm{CF}_{3}$ group on position 4 of the acceptor. Through the above analysis, it can be concluded that, for different positions of the acceptor, the molecules at acceptor positions 2 and 3 are designed to be better than the acceptors designed at positions 1 and 4; for different groups, the designed molecules inserted by the $-\mathrm{CN}$ group have the highest $\beta_{\text {tot }}$, while the dye inserted by the $-\mathrm{CF}_{3}$ group has the worst performance. Therefore, by inserting the $-\mathrm{CN}$ group, the molecules can have more obvious ICT. The lifetime $(t)$ of the designed molecules is listed in Table 13. Compared to the original molecule TY6 (3.91 ns), the majority of the molecules behaved better and are arranged in the following order: TY6$1 \mathrm{~A}>$ TY6-4A $>$ TY6-1C $>$ TY6- $1 \mathrm{~B}>$ TY6- $4 \mathrm{~B}>$ TY6-3C $>$ TY6$3 \mathrm{~B}>$ TY6-2A $=$ TY6 $>$ TY6-2B $>$ TY6-3A $>$ TY6-4C $>$ TY6-2C. 
TABLE 12: Calculated transition energies $(E)$ and oscillator strengths $(f)$ of TY6-X.

\begin{tabular}{|c|c|c|c|c|c|}
\hline Dye & State & Contribution Mo & $E(\mathrm{eV})$ & Absorption peak $\lambda(\mathrm{nm})$ & Strength $f$ \\
\hline \multirow{3}{*}{ TY6-1A } & 1 & $0.64911 \mathrm{H}-\mathrm{L}$ & 2.61 & 474 & 0.7379 \\
\hline & 2 & $0.64184 \mathrm{H}-1-\mathrm{L}$ & 3.19 & 389 & 0.3080 \\
\hline & 3 & $0.46081 \mathrm{H}-\mathrm{L}+1$ & 3.72 & 333 & 0.1848 \\
\hline \multirow{3}{*}{ TY6-2A } & 1 & $0.62146 \mathrm{H}-\mathrm{L}$ & 2.55 & 487 & 0.9095 \\
\hline & 2 & $0.60609 \mathrm{H}-1-\mathrm{L}$ & 3.11 & 399 & 0.3775 \\
\hline & 3 & $0.49844 \mathrm{H}-\mathrm{L}+1$ & 3.56 & 349 & 0.1175 \\
\hline \multirow{3}{*}{ TY6-3A } & 1 & $0.63567 \mathrm{H}-\mathrm{L}$ & 2.61 & 476 & 0.9494 \\
\hline & 2 & $0.60880 \mathrm{H}-1-\mathrm{L}$ & 3.16 & 392 & 0.3024 \\
\hline & 3 & $0.51245 \mathrm{H}-\mathrm{L}+1$ & 3.61 & 344 & 0.1524 \\
\hline \multirow{3}{*}{ TY6-4A } & 1 & $0.63494 \mathrm{H}-\mathrm{L}$ & 2.59 & 478 & 0.7723 \\
\hline & 2 & $0.62841 \mathrm{H}-1-\mathrm{L}$ & 3.14 & 395 & 0.3537 \\
\hline & 3 & $0.48229 \mathrm{H}-\mathrm{L}+1$ & 3.66 & 339 & 0.1645 \\
\hline \multirow{3}{*}{ TY6-1B } & 1 & $0.61488 \mathrm{H}-\mathrm{L}$ & 2.57 & 482 & 0.8056 \\
\hline & 2 & $0.60560 \mathrm{H}-1-\mathrm{L}$ & 3.14 & 395 & 0.3335 \\
\hline & 3 & $0.46057 \mathrm{H}-\mathrm{L}+1$ & 3.59 & 345 & 0.1073 \\
\hline \multirow{3}{*}{ TY6-2B } & 1 & $0.59970 \mathrm{H}-\mathrm{L}$ & 2.52 & 492 & 0.9340 \\
\hline & 2 & $0.58364 \mathrm{H}-1-\mathrm{L}$ & 3.09 & 402 & 0.3819 \\
\hline & 3 & $0.46337 \mathrm{H}-\mathrm{L}+1$ & 3.51 & 353 & 0.0761 \\
\hline \multirow{3}{*}{ TY6-3B } & 1 & $0.60186 \mathrm{H}-\mathrm{L}$ & 2.52 & 492 & 0.9248 \\
\hline & 2 & $0.58604 \mathrm{H}-1-\mathrm{L}$ & 3.09 & 401 & 0.3789 \\
\hline & 3 & $0.46237 \mathrm{H}-\mathrm{L}+1$ & 3.51 & 353 & 0.0761 \\
\hline \multirow{3}{*}{ TY6-4B } & 1 & $0.60783 \mathrm{H}-\mathrm{L}$ & 2.54 & 489 & 0.8887 \\
\hline & 2 & $0.59154 \mathrm{H}-1-\mathrm{L}$ & 3.10 & 400 & 0.3533 \\
\hline & 3 & $0.48002 \mathrm{H}-\mathrm{L}+1$ & 3.52 & 352 & 0.0757 \\
\hline \multirow{3}{*}{ TY6-1C } & 1 & $0.64038 \mathrm{H}-\mathrm{L}$ & 2.59 & 479 & 0.7841 \\
\hline & 2 & $0.63212 \mathrm{H}-1-\mathrm{L}$ & 3.16 & 393 & 0.3601 \\
\hline & 3 & $0.49671 \mathrm{H}-\mathrm{L}+1$ & 3.66 & 338 & 0.1861 \\
\hline \multirow{3}{*}{ TY6-2C } & 1 & $0.63810 \mathrm{H}-\mathrm{L}$ & 2.61 & 476 & 0.9726 \\
\hline & 2 & $0.60898 \mathrm{H}-1-\mathrm{L}$ & 3.17 & 391 & 0.3018 \\
\hline & 3 & $0.51590 \mathrm{H}-\mathrm{L}+1$ & 3.60 & 344 & 0.1599 \\
\hline \multirow{3}{*}{ TY6-3C } & 1 & $0.63042 \mathrm{H}-\mathrm{L}$ & 2.56 & 485 & 0.8984 \\
\hline & 2 & $0.61512 \mathrm{H}-1-\mathrm{L}$ & 3.12 & 397 & 0.3732 \\
\hline & 3 & $0.50881 \mathrm{H}-\mathrm{L}+1$ & 3.58 & 346 & 0.1387 \\
\hline \multirow{3}{*}{ TY6-4C } & 1 & $0.64020 \mathrm{H}-\mathrm{L}$ & 2.62 & 473 & 0.9611 \\
\hline & 2 & $0.61318 \mathrm{H}-1-\mathrm{L}$ & 3.17 & 391 & 0.3012 \\
\hline & 3 & $0.50465 \mathrm{H}-\mathrm{L}+1$ & 3.62 & 342 & 0.1880 \\
\hline
\end{tabular}

The maximum value of $t$ appears at TY6-1A (4.57 ns), which adds $\mathrm{a}-\mathrm{CF}_{3}$ group on position 3 of the acceptor; the minimum value of $t$ occurs at TY6-2C (3.48 ns), which adds a $-\mathrm{F}$ group on position 2 of the acceptor. Through the above analysis, we can get some conclusions: Molecules designed at position 1 of the acceptor have a longer lifetime. The lifetime of the designed molecules inserted at position 2 of the acceptor is lower than that of the original molecule (TY6), which is contrary to the conclusion that positions 2 and 3 are better than positions 1 and 4 . However, there is no significant difference between the different groups.

\section{Conclusion}

In this study, the DFT and TD-DFT methods were used to calculate the properties of the ground and excited states for MS3, TY3, and TY6. The calculated results show that TY6 has the highest HOMO energy compared to MS3 and TY3, resulting in the smallest energy gap. Smaller energy gaps favor the red-shifted absorption; so, TY6 has the most pronounced red-shifted absorption and the highest molar extinction coefficient, which results in more effective absorption of sunlight. TY6 not only has the largest EA and the lowest IP but also has lower hole/electron reorganization 
TABLE 13: Chemical reactivity parameters $(\mathrm{eV})$, light harvesting efficiencies (LHE), hyperpolarizabilities $\left(\beta_{\text {tot }}\right)$, and lifetime $(t)$.

\begin{tabular}{lcccccc}
\hline & EA & $\omega^{+}$ & $\omega$ & LHE & $\beta_{\text {tot }}$ & $\tau(\mathrm{ns})$ \\
\hline TY6-1A & 1.37 & 1.40 & 2.86 & 0.817 & 589,038 & 4.57 \\
TY6-2A & 1.55 & 1.63 & 3.15 & 0.877 & 909,491 & 3.91 \\
TY6-3A & 1.64 & 1.77 & 3.30 & 0.888 & 963,150 & 3.57 \\
TY6-4A & 1.43 & 1.47 & 2.95 & 0.831 & 529,611 & 4.43 \\
TY6-1B & 1.50 & 1.56 & 3.07 & 0.844 & $1,030,142$ & 4.33 \\
TY6-2B & 1.64 & 1.75 & 3.31 & 0.884 & 967,198 & 3.88 \\
TY6-3B & 1.64 & 1.75 & 3.31 & 0.881 & $1,068,163$ & 3.92 \\
TY6-4B & 1.59 & 1.68 & 3.22 & 0.871 & 818,100 & 4.02 \\
TY6-1C & 1.35 & 1.37 & 2.83 & 0.836 & 833,292 & 4.39 \\
TY6-2C & 1.58 & 1.68 & 3.20 & 0.893 & 815,616 & 3.48 \\
TY6-3C & 1.48 & 1.53 & 3.03 & 0.874 & 803,191 & 3.93 \\
TY6-4C & 1.52 & 1.60 & 3.09 & 0.891 & 755,814 & 3.49 \\
\hline
\end{tabular}

energies for higher hole and electron transfer. Through orbital and NBO analysis, the D-A- $\pi$-A (TY6) structure enhances the donoring electron ability and acceptor ability of receiving electrons. At the same time, TY6 also has the highest $\beta$ and the most obvious ICT. Through ESP analysis, we can find that TY6 has better reactivity. TY6 has the lowest $h$ and the highest LHE, $\Delta G^{\text {inject }}, \Delta G_{\text {dye }}^{\text {regen }}$, and $\omega^{+}$, which leads to higher $J_{\mathrm{SC}}$. A higher $\mu_{\text {normal }}$ results in a higher $V_{\mathrm{OC}}$. This is consistent with the experimental results that TY6 has the highest $J_{\mathrm{SC}}$ and $V_{\mathrm{OC}}$.

The calculated results for the design molecules show that the overall effect is improved to some extent. For different groups, by introducing the $-\mathrm{CN}$ group, the LUMO energy and energy gap can be reduced, leading to an obvious redshifted absorption. Chemical reactivity parameters and $\beta$ were significantly improved. For the different positions of the molecular acceptors, the positions away from the acceptors (positions 2 and 3) performed better than the other positions did. Especially, the oscillator strength led to a significant increase in LHE. Therefore, it will be of some reference to molecular design.

\section{Data Availability}

The three molecules (MS3, TY3, and TY6) used in this article and the experimental data mentioned were obtain from $[36,37]$, and other data were calculated using software such as the Gaussian 09 package. In addition, other data generated or analyzed during this study are available from the first and corresponding authors on reasonable request.

\section{Conflicts of Interest}

The authors declare that there is no conflict of interest regarding the publication of this article.

\section{Acknowledgments}

This work was supported by the Fundamental Research Funds for the Central Universities (2572018BC24), the China
Postdoctoral Science Foundation (2016 M590270), the Heilongiiang Postdoctoral Science Foundation (Grant LBHZ15002), the National Natural Science Foundation of China (Grant no. 11404055), and the college students' innovation project of the Northeast Forestry University (201709000001).

\section{References}

[1] S. Zhang, X. Yang, Y. Numata, and L. Han, "Highly efficient dye-sensitized solar cells: progress and future challenges," Energy \& Environmental Science, vol. 6, no. 5, pp. 14431464, 2013.

[2] M. Grätzel, "Photoelectrochemical cells," Nature, vol. 414, no. 6861 , pp. $338-344,2001$.

[3] M. Grätzel, "Recent advances in sensitized mesoscopic solar cells," Accounts of Chemical Research, vol. 42, no. 11, pp. 1788-1798, 2009.

[4] S. Ahmad, E. Guillén, L. Kavan, M. Grätzel, and M. K. Nazeeruddin, "Metal free sensitizer and catalyst for dye sensitized solar cells," Energy \& Environmental Science, vol. 6, no. 12, pp. 3439-3466, 2013.

[5] B. O'Regan and M. Grätzel, "A low-cost, high-efficiency solar cell based on dye-sensitized colloidal TiO2 films," Nature, vol. 353, no. 6346, pp. 737-740, 1991.

[6] J. Wu, Z. Lan, J. Lin et al., "Electrolytes in dye-sensitized solar cells," Chemical Reviews, vol. 115, no. 5, pp. 2136-2173, 2015.

[7] V. Sugathan, E. John, and K. Sudhakar, "Recent improvements in dye sensitized solar cells: a review," Renewable and Sustainable Energy Reviews, vol. 52, pp. 54-64, 2015.

[8] N. Robertson, "Optimizing dyes for dye-sensitized solar cells," Angewandte Chemie International Edition, vol. 45, no. 15, pp. 2338-2345, 2006.

[9] Y.-S. Yen, H. H. Chou, Y. C. Chen, C. Y. Hsu, and J. T. Lin, "Recent developments in molecule-based organic materials for dye-sensitized solar cells," Journal of Materials Chemistry, vol. 22, no. 18, pp. 8734-8747, 2012.

[10] A. Yella, C. L. Mai, S. M. Zakeeruddin et al., "Molecular engineering of push-pull porphyrin dyes for highly efficient dye-sensitized solar cells: the role of benzene spacers," Angewandte Chemie, vol. 53, no. 11, pp. 2973-2977, 2014.

[11] A. Mishra, M. K. R. Fischer, and P. Bäuerle, "Metal-free organic dyes for dye-sensitized solar cells: from structure: property relationships to design rules," Angewandte Chemie International Edition, vol. 48, no. 14, pp. 2474-2499, 2009.

[12] S.-W. Wang, C. C. Chou, F. C. Hu et al., "Panchromatic Ru(ii) sensitizers bearing single thiocyanate for high efficiency dye sensitized solar cells," Journal of Materials Chemistry A, vol. 2, no. 41, pp. 17618-17627, 2014.

[13] M. K. Nazeeruddin, A. Kay, I. Rodicio et al., "Conversion of light to electricity by cis-X2bis $(2,2$ '-bipyridyl-4,4'-dicarboxylate)ruthenium(II) charge-transfer sensitizers (X $=\mathrm{Cl}-, \mathrm{Br}-$, I-, $\mathrm{CN}-$, and $\mathrm{SCN}-$ ) on nanocrystalline titanium dioxide electrodes," Journal of the American Chemical Society, vol. 115, no. 14, pp. 6382-6390, 1993.

[14] T. Bessho, S. . M. Zakeeruddin, C. Y. Yeh, E. . W. G. Diau, and M. Grätzel, "Highly efficient mesoscopic dye-sensitized solar cells based on donor-acceptor-substituted porphyrins," Angewandte Chemie International Edition, vol. 49, no. 37, pp. 6646-6649, 2010.

[15] T. Higashino and H. Imahori, "Porphyrins as excellent dyes for dye-sensitized solar cells: recent developments and 
insights," Dalton Transactions, vol. 44, no. 2, pp. 448-463, 2015.

[16] S. Collavini, S. F. Völker, and J. L. Delgado, "Understanding the outstanding power conversion efficiency of perovskitebased solar cells," Angewandte Chemie International Edition, vol. 54, no. 34, pp. 9757-9759, 2015.

[17] Y. Zhao and K. Zhu, "Organic-inorganic hybrid lead halide perovskites for optoelectronic and electronic applications," Chemical Society Reviews, vol. 45, no. 3, pp. 655-689, 2016.

[18] M. A. Green, A. Ho-Baillie, and H. J. Snaith, "The emergence of perovskite solar cells," Nature Photonics, vol. 8, no. 7, pp. 506-514, 2014.

[19] Y. Rong, L. Liu, A. Mei, X. Li, and H. Han, "Beyond efficiency: the challenge of stability in mesoscopic perovskite solar cells," Advanced Energy Materials, vol. 5, no. 20, article 1501066, 2015.

[20] A. Yella, C. L. Mai, S. M. Zakeeruddin et al., "Molecular engineering of push-pull porphyrin dyes for highly efficient dye-sensitized solar cells: the role of benzene spacers," Angewandte Chemie, vol. 126, no. 11, pp. 3017-3021, 2014.

[21] Z. Yao, M. Zhang, H. Wu, L. Yang, R. Li, and P. Wang, "Donor/acceptor indenoperylene dye for highly efficient organic dye-sensitized solar cells," Journal of the American Chemical Society, vol. 137, no. 11, pp. 3799-3802, 2015.

[22] M. Liang and J. Chen, "Arylamine organic dyes for dyesensitized solar cells," Chemical Society Reviews, vol. 42, no. 8, pp. 3453-3488, 2013.

[23] Y. S. Tingare, M. T. Shen, C. Su et al., "Novel oxindole based sensitizers: synthesis and application in dye-sensitized solar cells," Organic Letters, vol. 15, no. 17, pp. 4292-4295, 2013.

[24] Y. Wu and $\mathrm{W}$. Zhu, "Organic sensitizers from D- $\pi-\mathrm{A}$ to $\mathrm{D}-\mathrm{A}-\pi-\mathrm{A}$ : effect of the internal electron-withdrawing units on molecular absorption, energy levels and photovoltaic performances," Chemical Society Reviews, vol. 42, no. 5, pp. 2039-2058, 2013.

[25] Y. Wu, W. H. Zhu, S. M. Zakeeruddin, and M. Grätzel, "Insight into $\mathrm{D}-\mathrm{A}-\pi-\mathrm{a}$ structured sensitizers: a promising route to highly efficient and stable dye-sensitized solar cells," ACS Applied Materials \& Interfaces, vol. 7, no. 18, pp. 93079318, 2015.

[26] K. Kakiage, Y. Aoyama, T. Yano, K. Oya, J. I. Fujisawa, and M. Hanaya, "Highly-efficient dye-sensitized solar cells with collaborative sensitization by silyl-anchor and carboxyanchor dyes," Chemical Communications, vol. 51, no. 88, pp. 15894-15897, 2015.

[27] P. Bazylewski, K. H. Kim, D. H. Choi, and G. S. Chang, "Selfordering properties of functionalized Acenes for annealingfree organic thin film transistors," The Journal of Physical Chemistry B, vol. 117, no. 36, pp. 10658-10664, 2013.

[28] H. Cha, D. S. Chung, S. Y. Bae et al., "Complementary absorbing star-shaped small molecules for the preparation of ternary cascade energy structures in organic photovoltaic cells," Advanced Functional Materials, vol. 23, no. 12, pp. 15561565, 2013.

[29] P. Zhang, W. Dou, Z. Ju et al., “A 9,9'-bianthracene-cored molecule enjoying twisted intramolecular charge transfer to enhance radiative-excitons generation for highly efficient deep-blue OLEDs," Organic Electronics, vol. 14, no. 3, pp. 915-925, 2013.

[30] C. Teng, X. Yang, C. Yang et al., "Molecular design of anthracene-bridged metal-free organic dyes for efficient dye- sensitized solar cells," The Journal of Physical Chemistry C, vol. 114, no. 19, pp. 9101-9110, 2010.

[31] I. T. Choi, B. S. You, Y. K. Eom et al., "Triarylamine-based dual-function coadsorbents with extended $\pi$-conjugation aryl linkers for organic dye-sensitized solar cells," Organic Electronics, vol. 15, no. 11, pp. 3316-3326, 2014.

[32] V. Mallam, H. Elbohy, Q. Qiao, and B. A. Logue, "Investigation of novel anthracene-bridged carbazoles as sensitizers and Co-sensitizers for dye-sensitized solar cells," International Journal of Energy Research, vol. 39, no. 10, pp. 1335-1344, 2015.

[33] C.-L. Wang, P. T. Lin, Y. F. Wang et al., "Cost-effective anthryl dyes for dye-sensitized cells under one sun and dim light," The Journal of Physical Chemistry C, vol. 119, no. 43, pp. 2428224289, 2015.

[34] Y.-S. Yen, Y. C. Chen, H. H. Chou, S. T. Huang, and J. T. Lin, "Novel organic sensitizers containing 2,6-difunctionalized anthracene unit for dye sensitized solar cells," Polymer, vol. 4, no. 3, pp. 1443-1461, 2012.

[35] C.-L. Mai, T. Moehl, Y. Kim et al., "Acetylene-bridged dyes with high open circuit potential for dye-sensitized solar cells," RSC Advances, vol. 4, no. 66, pp. 35251-35257, 2014.

[36] Y. S. Tingare, N. S.'. Vinh, H. H. Chou et al., "New acetylenebridged 9,10-conjugated anthracene sensitizers: application in outdoor and indoor dye-sensitized solar cells," Advanced Energy Materials, vol. 7, no. 18, article 1700032, 2017.

[37] C. Lee, W. Yang, and R. G. Parr, "Development of the ColleSalvetti correlation-energy formula into a functional of the electron density," Physical Review B, vol. 37, no. 2, pp. 785789, 1988.

[38] P. J. Stephens, F. J. Devlin, C. F. Chabalowski, and M. J. Frisch, "Ab initio calculation of vibrational absorption and circular dichroism spectra using density functional force fields," The Journal of Physical Chemistry, vol. 98, no. 45, pp. 1162311627, 1994.

[39] B. J. Lynch, P. L. Fast, M. Harris, and D. G. Truhlar, “Adiabatic connection for kinetics," The Journal of Physical Chemistry A, vol. 104, no. 21, pp. 4811-4815, 2000.

[40] A. D. Becke, "Density-functional thermochemistry. III. The role of exact exchange," The Journal of Chemical Physics, vol. 98, no. 7, pp. 5648-5652, 1993.

[41] M. Cossi, V. Barone, B. Mennucci, and J. Tomasi, “Ab initio study of ionic solutions by a polarizable continuum dielectric model," Chemical Physics Letters, vol. 286, no. 3-4, pp. 253260, 1998.

[42] R. E. Stratmann, G. E. Scuseria, and M. J. Frisch, “An efficient implementation of time-dependent density-functional theory for the calculation of excitation energies of large molecules," The Journal of Chemical Physics, vol. 109, no. 19, pp. 82188224, 1998.

[43] T. Yanai, D. P. Tew, and N. C. Handy, "A new hybrid exchange-correlation functional using the Coulombattenuating method (CAM-B3LYP)," Chemical Physics Letters, vol. 393, no. 1-3, pp. 51-57, 2004.

[44] J. P. Foster and F. Weinhold, "Natural hybrid orbitals," Journal of the American Chemical Society, vol. 102, no. 24, pp. 72117218, 1980.

[45] M. J. Gwt, H. B. Frisch, G. E. Schlegel et al., Gaussian 09, Revision A.01, Gaussian, Inc, Wallingford, 2009.

[46] Y. Mo, Z. Lin, W. Wu, and Q. Zhang, "Bond-distorted orbitals and effects of hybridization and resonance on $\mathrm{C}-\mathrm{C}$ bond 
lengths," The Journal of Physical Chemistry, vol. 100, no. 28, pp. 11569-11572, 1996.

[47] M. Kręglewski, "The geometry and inversion-internal rotation potential function of methylamine," Journal of Molecular Spectroscopy, vol. 133, no. 1, pp. 10-21, 1989.

[48] L. X. Wang, Y. Liu, X. L. Tuo, N. Song, and X. G. Wang, "Effect of $\mathrm{H}+$ and $\mathrm{NH} 4+$ on the N-NO2 bond dissociation energy of HMX," Acta Physico-Chimica Sinica, vol. 23, no. 10, pp. 1560-1564, 2007.

[49] Y. Li, C. Sun, D. Qi, P. Song, and F. Ma, "Effects of different functional groups on the optical and charge transport properties of copolymers for polymer solar cells," RSC Advances, vol. 6, no. 66, pp. 61809-61820, 2016.

[50] P. Song, Y. Li, F. Ma, T. Pullerits, and M. Sun, "External electric field-dependent photoinduced charge transfer in a donor-acceptor system for an organic solar cell," The Journal of Physical Chemistry C, vol. 117, no. 31, pp. 15879-15889, 2013.

[51] C. G. Zhan, J. A. Nichols, and D. A. Dixon, "Ionization potential, electron affinity, electronegativity, hardness, and electron excitation energy: molecular properties from density functional theory orbital energies," The Journal of Physical Chemistry A, vol. 107, no. 20, pp. 4184-4195, 2003.

[52] G. Zhang and C. B. Musgrave, "Comparison of DFT methods for molecular orbital eigenvalue calculations," The Journal of Physical Chemistry A, vol. 111, no. 8, pp. 1554-1561, 2007.

[53] C. Sun, Y. Li, P. Song, and F. Ma, "An experimental and theoretical investigation of the electronic structures and photoelectrical properties of ethyl red and carminic acid for DSSC application," Materials, vol. 9, no. 10, p. 813, 2016.

[54] L. L. Estrella, M. P. Balanay, and D. H. Kim, "The effect of donor group rigidification on the electronic and optical properties of arylamine-based metal-free dyes for dye-sensitized solar cells: a computational study," The Journal of Physical Chemistry. A, vol. 120, no. 29, pp. 5917-5927, 2016.

[55] J. Martínez, "Local reactivity descriptors from degenerate frontier molecular orbitals," Chemical Physics Letters, vol. 478, no. 4-6, pp. 310-322, 2009.

[56] R. G. Parr and R. G. Pearson, "Absolute hardness: companion parameter to absolute electronegativity," Journal of the American Chemical Society, vol. 105, no. 26, pp. 7512-7516, 1983.

[57] J. L. Gázquez, A. Cedillo, and A. Vela, "Electrodonating and electroaccepting powers," The Journal of Physical Chemistry A, vol. 111, no. 10, pp. 1966-1970, 2007.

[58] R. G. Parr, L. v. Szentpály, and S. Liu, "Electrophilicity index," Journal of the American Chemical Society, vol. 121, no. 9, pp. 1922-1924, 1999.

[59] S. Kushwaha and L. Bahadur, "Enhancement of power conversion efficiency of dye-sensitized solar cells by co-sensitization of phloxine $\mathrm{B}$ and bromophenol blue dyes on $\mathrm{ZnO}$ photoanode," Journal of Luminescence, vol. 161, pp. 426-430, 2015.

[60] J. Preat, D. Jacquemin, C. Michaux, and E. A. Perpète, "Improvement of the efficiency of thiophene-bridged compounds for dye-sensitized solar cells," Chemical Physics, vol. 376, no. 1-3, pp. 56-68, 2010.

[61] J. Preat, C. Michaux, D. Jacquemin, and E. A. Perpète, "Enhanced efficiency of organic dye-sensitized solar cells: triphenylamine derivatives," The Journal of Physical Chemistry C, vol. 113, no. 38, pp. 16821-16833, 2009.
[62] J. B. Asbury, Y. Q. Wang, E. Hao, H. N. Ghosh, and T. Lian, "Evidences of hot excited state electron injection from sensitizer molecules to $\mathrm{TiO} 2$ nanocrystalline thin films," Research on Chemical Intermediates, vol. 27, no. 4-5, pp. 393-406, 2001.

[63] M. Salazar-Villanueva, A. Cruz-López, A. A. Zaldívar-Cadena, A. Tovar-Corona, M. L. Guevara-Romero, and O. VazquezCuchillo, "Effect of the electronic state of $\mathrm{Ti}$ on M-doped $\mathrm{TiO} 2$ nanoparticles $(\mathrm{M}=\mathrm{Zn}, \mathrm{Ga}$ or $\mathrm{Ge})$ with high photocatalytic activities: a experimental and DFT molecular study," Materials Science in Semiconductor Processing, vol. 58, pp. 8-14, 2017.

[64] T. Daeneke, A. J. Mozer, Y. Uemura et al., "Dye regeneration kinetics in dye-sensitized solar cells," Journal of the American Chemical Society, vol. 134, no. 41, pp. 16925-16928, 2012.

[65] G. Boschloo and A. Hagfeldt, "Characteristics of the iodide/ triiodide redox mediator in dye-sensitized solar cells," Accounts of Chemical Research, vol. 42, no. 11, pp. 18191826, 2009.

[66] Z. Yang, Y. Liu, C. Liu, C. Lin, and C. Shao, "TDDFT screening auxiliary withdrawing group and design the novel D-A- $\pi$-A organic dyes based on indoline dye for highly efficient dyesensitized solar cells," Spectrochimica Acta Part A: Molecular and Biomolecular Spectroscopy, vol. 167, pp. 127-133, 2016.

[67] M. Li, L. Kou, L. Diao et al., "Theoretical study of WS-9-based organic sensitizers for unusual Vis/NIR absorption and highly efficient dye-sensitized solar cells," The Journal of Physical Chemistry C, vol. 119, no. 18, pp. 9782-9790, 2015.

[68] Z. Ning, Y. Fu, and H. Tian, "Improvement of dye-sensitized solar cells: what we know and what we need to know," Energy \& Environmental Science, vol. 3, no. 9, p. 1170, 2010.

[69] J. Zhang, Y.-H. Kan, H.-B. Li, Y. Geng, Y. Wu, and Z.-M. Su, "How to design proper $\pi$-spacer order of the D- $\pi$-A dyes for DSSCs? A density functional response," Dyes and Pigments, vol. 95, no. 2, pp. 313-321, 2012.

[70] S. R. Marder, D. N. Beratan, and L.-T. Cheng, "Approaches for optimizing the first electronic hyperpolarizability of conjugated organic molecules," Science, vol. 252, no. 5002, pp. 103-106, 1991.

[71] M. Sun, Y. Ding, and H. Xu, "Direct visual evidence for quinoidal charge delocalization in poly-p-phenylene cation radical," The Journal of Physical Chemistry B, vol. 111, no. 46, pp. 13266-13270, 2007.

[72] Y. Li, S. Wang, Y. Lv, Y. Li, and Q. Wang, "Insight into optoelectronic property by modifying optical layers with multipolar and multi-branched structures," Journal of Materials Science: Materials in Electronics, vol. 28, no. 2, pp. 14891500, 2017.

[73] D. Matthews, P. Infelta, and M. Grätzel, "Calculation of the photocurrent-potential characteristic for regenerative, sensitized semiconductor electrodes," Solar Energy Materials and Solar Cells, vol. 44, no. 2, pp. 119-155, 1996.

[74] W.-Q. Deng, L. Sun, J. D. Huang, S. Chai, S. H. Wen, and K. L. Han, "Quantitative prediction of charge mobilities of $\pi$-stacked systems by first-principles simulation," Nature Protocols, vol. 10, no. 4, pp. 632-642, 2015.

[75] J. S. Murray and P. Politzer, "The electrostatic potential: an overview," Wiley Interdisciplinary Reviews: Computational Molecular Science, vol. 1, no. 2, pp. 153-163, 2011. 

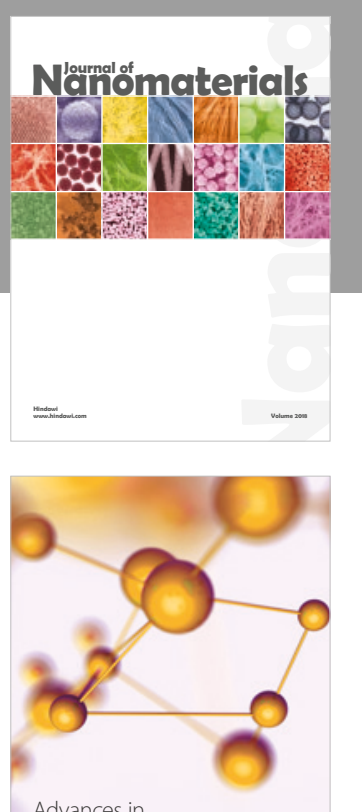

Physical Chemistry
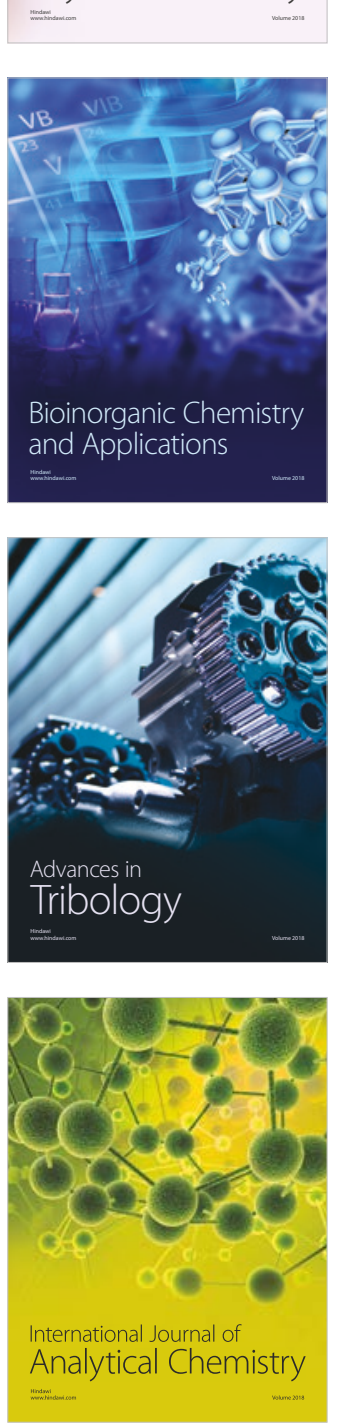

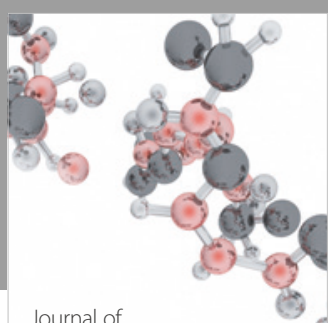

Analytical Methods

in Chemistry

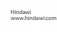

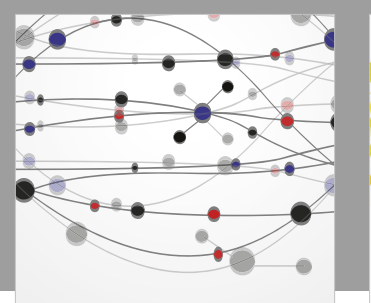

The Scientific World Journal

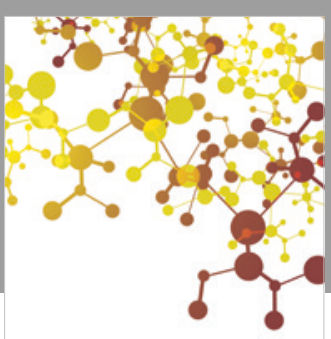

Journal of

Applied Chemistry
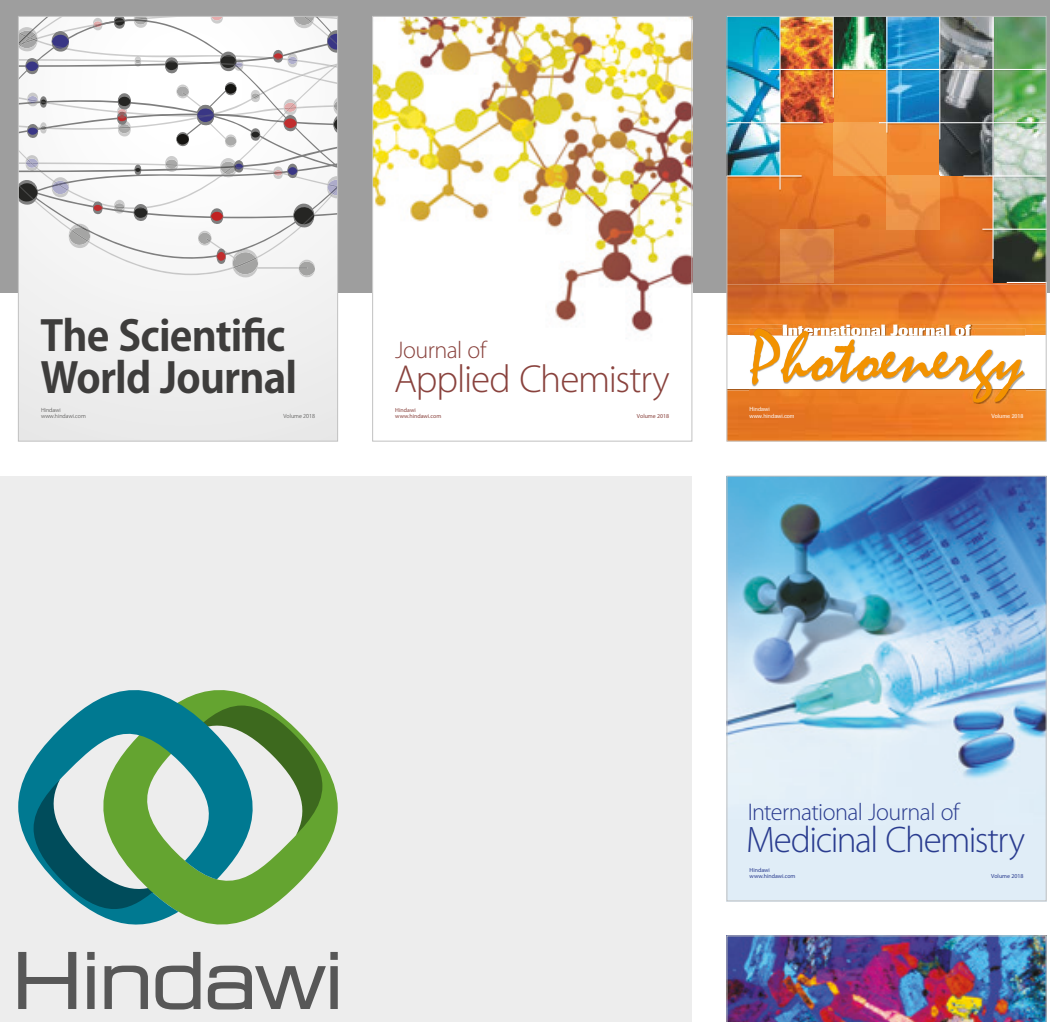

Submit your manuscripts at

www.hindawi.com
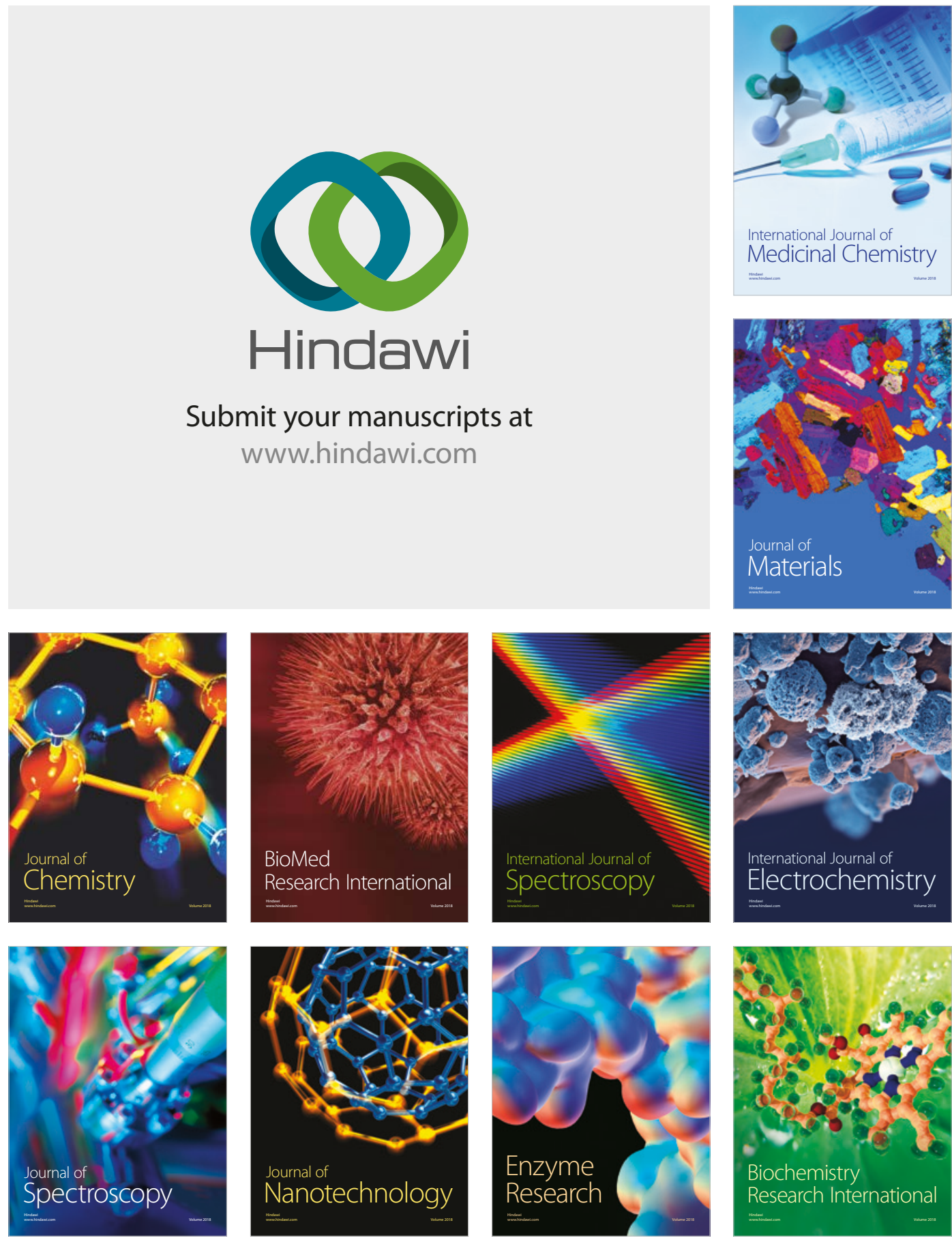
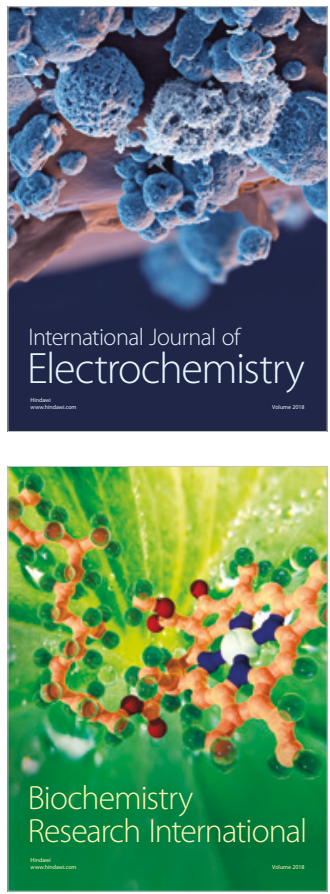